\title{
Índices de Criminalidade nos Municipios Paulistas: Efeitos Heterogêneos do Desenvolvimento Econômico nos Crimes Contra a Vida e Contra o Patrimônio
}

\author{
Luís Fernando Bezerra de Oliveira ${ }^{1}$ (D) | Carlos Cesar Santejo Saiani ${ }^{2}$ \\ ${ }^{1}$ Universidade Federal de Uberlândia, Uberlândia, MG, Brasil. E-mail: lfbezerra11@ufu.br \\ ${ }^{2}$ Universidade Federal de Uberlândia, Uberlândia, MG, Brasil. E-mail: ssaiani@ufu.br
}

\begin{abstract}
RESUMO
Este estudo mensurou índices de criminalidade dos municípios de São Paulo com o objetivo de investigar efeitos heterogêneos do desenvolvimento econômico no tempo e segundo categorias de crimes (contra a vida e contra o patrimônio), dimensões do próprio desenvolvimento (empregorenda e educação) e regiões do estado (região metropolitana, litoral e interior). A hipótese intrínseca às análises é que, quanto piores as condições socioeconômicas de uma localidade, maior o custo de oportunidade e, assim, menor tende a ser a criminalidade. Para atingir o objetivo, foram realizadas regressões em painel dinâmico com dados municipais de 2007 a 2016. Os resultados não refutaram a hipótese, principalmente pelas dimensões emprego-renda e educação se mostrarem, de forma robusta, como redutoras de crimes contra a vida. Porém, o mesmo não pode ser dito em relação aos crimes contra o patrimônio. Ademais, os resultados sinalizaram: componente inercial do crime e relações significativas entre a criminalidade, produtividade policial, armas de fogo e porte e tráfico de entorpecentes.
\end{abstract}

\section{PALAVRAS-CHAVE}

Criminalidade, Desenvolvimento econômico, Dados em painel

Crime Rates in São Paulo Municipalities: Heterogeneous Effects of Economic Development on Crimes Against Life and Property

\begin{abstract}
This study measured crime rates in the municipalities of São Paulo with the aim of investigating heterogeneous effects of economic development over time and according to crime categories (against life and property), dimensions of development (employment-income and education) and regions of the state (metropolitan region, coast, and interior). The hypothesis intrinsic to the analyzes is that the worse the socioeconomic conditions of a location, the higher the opportunity cost and, thus, the lower tends to be criminality. To achieve the objective, regressions were carried out in dynamic panel with municipal data from 2007 to 2016 . The results did not refute the hypothesis, mainly because the employment-income and educational dimensions were shown, in a robust way, to reduce crimes against life. However, the same cannot be said in relation to crimes against property. Furthermore, the results indicated: the inertial component of crime and significant relationships between crime, police productivity, firearms and trafficking, and the possession of narcotics.
\end{abstract}

KEYWORDS

Criminality, Economic development, Panel data

\section{CLASSIFICAÇÃO JEL}

R10, R1 1 


\section{Introdução}

A criminalidade resulta em diversas externalidades negativas, como a redução de atividades econômicas e a inibição da acumulação de capitais físico e humano. Para exemplificar, no auge dos roubos de cargas no Rio de Janeiro em 2017, 13\% das transportadoras decretaram falência, o custo do frete aumentou e, consequentemente, os preços de algumas mercadorias cresceram em até 30\% (CNI, 2018; Cerqueira et al., 2019). Além disso, a criminalidade gera perda prematura de vidas e aumento de dispêndios em segurança pública, saúde, aposentadorias precoces e indenizações das vítimas. Tais recursos poderiam ter outros destinos com externalidades positivas, como educação.

Vale destacar que o Brasil apresentava, em 2017, 30,5 homicídios por 100 mil habitantes, atrás apenas da Venezuela, na América do Sul (UNODC, 2019). Ressaltase que a Organização Mundial da Saúde já interpreta como um problema de saúde pública uma taxa acima de 10 casos por 100 mil habitantes. Assim, os brasileiros vivenciam uma grave crise de segurança pública, configurada pelo crescimento sistêmico das mortes violentas (Waiselfisz, 2016). Por outro lado, a realidade de São Paulo destoa de boa parte do restante do país. Os municípios paulistas ostentaram redução de 47\% dos homicídios dolosos entre os anos de 2006 e 2016 (Cerqueira et al., 2018), além de terem, em 2018, uma taxa de 10,7 mortes violentas por 100 mil habitantes, a menor entre os estados brasileiros.

Devido às especificidades da dinâmica da taxa de homicídios em São Paulo, esse estado tornou-se objeto de estudo de vários trabalhos que tentam entender os condicionantes da queda da violência. Tais trabalhos, no geral, centram esforços em explicar somente os crimes de homicídio doloso; porém, a criminalidade abarca um leque amplo de delitos, como roubos e furtos, que possuem fundamental importância na determinação da vitimização em dado local. É justamente para tal lacuna na literatura que este estudo pretende contribuir ao expandir as análises da criminalidade em São Paulo a outros tipos de delitos por meio da criação de índices sintéticos de criminalidade dos municípios paulistas.

Seguindo a classificação do Código Penal brasileiro, são calculados índices de crimes contra a vida e o patrimônio. Com esses, é caracterizada a distribuição regional do crime no estado, com ênfase à divisão dos municípios em região metropolitana (e capital), litoral e interior e à comparação entre esses recortes, aproximando, assim, a discussão também de uma questão de desenvolvimento regional.

Fundamentando-se na literatura econômica do crime, em especial em Becker (1968), é plausível esperar que, em locais com melhores indicadores de desenvolvimento econômico, as pessoas possuam mais e melhores oportunidades de trabalho no mercado formal, o que acaba por elevar os custos de oportunidade da prática delituosa. Assim, a escolha pelo mercado lícito vis-à-vis o ilícito torna-se mais atrativa. Em contrapartida, locais com piores indicadores de desenvolvimento tendem a deter con- 
dições inapropriadas de acesso a bens e serviços básicos à vida humana. Com isso, os indivíduos podem procurar outras formas de garantir a sobrevivência, como o tráfico de drogas, atividade que está intimamente relacionada à violência. Além disso, melhores indicadores de acesso à educação podem agir no sentido de elevar os custos morais e a expectativa de rendimentos futuros e, com isso, reduzir os indicadores de criminalidade. Por outro lado, melhoras nos padrões de vida podem atrair mais criminosos em função dos ganhos potenciais líquidos vislumbrados, elevando a criminalidade.

Assim, os efeitos de dimensões do desenvolvimento (emprego-renda e educação) nos tipos de crimes (contra a vida ou o patrimônio) podem ser heterogêneos. Para testar essa hipótese, após apresentar os índices sintéticos de criminalidade, o estudo os utiliza em análises descritivas para caracterizar a situação do estado. Já em estimações econométricas por System-GMM, eles são as variáveis dependentes para um painel de municípios paulistas com informações de 2007 a 2016. Por meio dessas estimações, é que são atingidos os objetivos principais do estudo: i) investigar os efeitos do desenvolvimento econômico nos índices municipais de criminalidade; e ii) avaliar se tais efeitos são heterogêneos no tempo e segundo as categorias de crimes (vida e patrimônio), as dimensões do desenvolvimento (emprego-renda e educação) e as regiões do estado (região metropolitana, litoral e interior). Como proxies para dimensões do desenvolvimento dos municípios paulistas são utilizados os Índices FIRJAN de Desenvolvimento Municipal (componentes emprego-renda e educação).

Além desta introdução (primeira seção), este estudo está estruturado em mais cinco seções. A subsequente (segunda) apresenta um breve referencial teórico e uma revisão de trabalhos empíricos com dados, variáveis, estratégias e evidências que embasam as análises. A terceira seção apresenta os índices sintéticos de criminalidade. Na quarta, são discutidas as estratégias empíricas para alcançar os objetivos. A quinta contém as análises dos resultados. A sexta apresenta as considerações finais.

\section{Criminalidade e desenvolvimento econômico: uma breve revisão bibliográfica}

A Economia do Crime abrange algumas abordagens teóricas sobre o tema e que podem se valer de discussões de variados campos do conhecimento. Este estudo foca seus esforços na investigação de determinantes da criminalidade, optando por se fundamentar na Teoria da Escolha Racional, que pressupõe o indivíduo como um agente racional que decide ou não ingressar no "mundo do crime" pela comparação entre os ganhos e as perdas de práticas criminosas e os ganhos esperados no mercado de trabalho legal. Dentre as inúmeras variáveis a serem consideradas na decisão, destacam-se: renda, acesso a serviços sociais, eficiência policial e educação (Cerqueira e Lobao, 2003; Mariano, 2010; Britto, 2017). No geral, essa discussão é embasada pelo modelo de Becker (1968). 
Becker (1968) formaliza matematicamente o seu modelo com base na Teoria Microeconômica. O crime é considerado uma atividade econômica que gera retornos financeiros. O indivíduo opta por praticar ou não um ato ilícito comparando tais retornos aos custos. Assim, ele busca maximizar sua utilidade pela alocação ótima de seus recursos e tomando alguns custos específicos como restrições. Sucintamente, o ato criminoso é efetivado se os seus ganhos superarem o custo de oportunidade.

No modelo de Becker (1968), o comportamento de cada indivíduo j é representado pela equação $O_{j}=O_{j}\left[b, f_{j}(p), \tau_{j}\right]$. Conhecida na literatura como "o lado da oferta do crime", esta equação corresponde ao total de crimes $\left(O_{j}\right)$ a serem cometidos em função: i) dos ganhos pretendidos com a prática criminosa (b); ii) da probabilidade de ser preso (p); e iii) da intensidade da punição se for pego e condenado $(f)$. Considera-se, ainda, um vetor de variáveis $\tau$ que influencia a decisão de cometer um crime.

O modelo de Becker (1968) é bastante simplificado e, assim, possui limitações. Ele não capta, por exemplo, todos os aspectos necessários para mensurar o custo social do crime - como o valor de uma vida perdida. Porém, é o que melhor se adequa às análises deste estudo. Para isso, cabe ponderar mais sobre atributos que podem estar contidos no vetor $\tau$, com ênfase em fatores socioeconômicos, dado o objetivo do presente estudo. Espinheira (2006) evidencia o papel das instituições responsáveis por satisfazer necessidades sociais básicas e sustentar a não ocorrência de desvios comportamentais: família, Estado, escola, entidades religiosas e empresa (trabalho), entre outros. Ademais, salienta os fatores atrelados à origem da prática criminosa, como: tendências criminais, situação ambiental e resistências mentais. Este estudo associa-se ao debate de fatores ambientais (externos) que afetam o comportamento individual, i.e., os atributos socioeconômicos do ambiente do potencial transgressor ${ }^{1}$.

Fernandes e Fernandes (2002) e Britto (2017) apontam como principais condicionantes sociais do desvio de comportamento dos indivíduos pró-crime a falta de condições de subsistência, educação, vigilância e justiça. Em relação à primeira, é pressuposto que os cidadãos que detêm baixo acesso a uma vida digna têm maior propensão a praticarem atos criminosos à procura de maiores rendas. Pela segunda, acredita-se que pessoas sem acesso à educação de qualidade não têm boas oportunidades no mercado formal, assim, podem obter no mercado ilícito uma forma de sobreviverem. No que tange à terceira, assume-se que locais sem condições de vigilância são mais propensos a práticas criminosas. Finalmente, a quarta causa destaca a importância da justiça no sentido de dissuadir o ato criminoso.

Tais aspectos estão próximos à noção de qualidade de vida pela visão das capacitações. Assim, considera-se desenvolvimento econômico neste estudo como algo coerente à definição de Sen (2000), a qual postula que o desenvolvimento (humano) é

\footnotetext{
${ }^{1}$ Conforme apontam Plassa et al. (2019), visões alternativas às da racionalidade de Becker (1968) utilizadas para justificar determinantes da criminalidade, como as derivadas da teoria da desorganização social de Shaw e Mckay (1942) e da tensão social de Merton (1938), também destacam o papel de condicionantes socioeconômicos.
} 
maior quanto mais são expandidas as liberdades individuais. Desse modo, é advogado que o desenvolvimento deve estar atrelado, acima de tudo, a melhorias das condições de vida dos cidadãos pelo fortalecimento de suas liberdades, como os direitos à educação de qualidade, saúde e segurança, dentre outros (Marchezini e Kuwahara, 2018).

Em vista disso, defende-se que a criminalidade tem uma íntima relação com o desenvolvimento econômico, pois locais mais desenvolvidos possuem mais e melhor acesso a bens e serviços públicos e melhores oportunidades de trabalho no mercado formal, fatores que elevam o custo de oportunidade para um indivíduo ingressar na atividade ilícita (Becker, 1968). Por outro ângulo, a criminalidade também obstaculiza o desenvolvimento econômico por várias razões. Por exemplo, criminalidade alta inibe potenciais investimentos devido às externalidades negativas do crime, além de gerar alocação de recursos para a segurança pública que poderiam ser investidos em outras áreas mais produtivas.

Alguns trabalhos avaliam empiricamente a possivel e complexa relação entre desenvolvimento e criminalidade. Shikida (2008), por exemplo, calcula um índice de desenvolvimento socioeconômico para os municípios paranaenses com dados de 2005 e o relaciona a crimes violentos (homicídios), obtendo uma correlação negativa (fraca). Assim, sugere queda desses crimes com o desenvolvimento.

Mariano (2010) investiga os impactos de indicadores socioeconômicos nos crimes contra a vida e o patrimônio nos municípios paulistas com dados de 2000 e estimações pelo método de Mínimos Guadrados Ordinários. Como proxies para o desenvolvimento, utiliza: o PIB per capita, o nível de ocupação, a escolaridade (anos de estudo) e o Índice de Gini (desigualdade). Além disso, controla atributos comumente associados ao grau de criminalidade (policiais, uso de entorpecentes e tráfico).

Os resultados de Mariano (2010) indicam que apenas o PIB per capita e o total de policiais não são capazes de explicar os crimes contra o patrimônio, o que é justificado pela heterogeneidade dos municípios paulistas. Ademais, os coeficientes das variáveis explicativas, exceto do total de policiais, são positivos. Para o caso da ocupação, o autor aponta três justificativas para o resultado. O aumento do nível de ocupação: i) atenua o custo de oportunidade do potencial transgressor ao elevar ganhos em atividades legais; ii) impede a depreciação do capital humano decorrente do tempo de ausência no mercado de trabalho; e iii) eleva a riqueza disponivel, aumentando os ganhos potenciais para os criminosos e, por conseguinte, a criminalidade. Por fim, quanto ao efeito benéfico dos anos de estudo, o autor explica que a maior escolaridade também eleva o custo de oportunidade do crime, pois uma pessoa educada tende a obter melhores vagas no mercado de trabalho e, assim, maior remuneração.

Para os municípios brasileiros, Silva (2013), empregando o método de correlação de variáveis e testes de hipóteses com a implementação de Análises de Variância, avalia as relações entre a taxa de homicídios e os Índices FIRJAN de Desenvolvimento Municipal (IFDM) entre os anos de 2005 e 2009. O trabalho evidencia que o com- 
ponente emprego-renda do Índice FIRJAN não é correlacionado à taxa de homicídio municipal, ao contrário do IFDM pelo componente de educação, sendo negativo o sinal dessa correlação - o que sugere que melhores condições educacionais reduzem crimes brutais.

Oliveira (2016) avalia o impacto do programa "Pacto Pela Vida" (PPV), de 2007, nas taxas de homicídios dos municípios de Pernambuco de 2007 a 2013. Para isso, são realizadas regressões por Mínimos Quadrados Ordinários nas quais as proxies para o desenvolvimento são os três componentes do Índice FIRJAN: saúde, emprego-renda e educação. O componente educação reportou significância e sinal negativo, assim como em outros trabalhos com distintas amostras e estratégias (Kume, 2004; Teixeira, 2011; Silva, 2013). O componente saúde não é significativo em todos os modelos. O componente emprego-renda é associado a efeito significativo e positivo (aumento) dos homicídios.

Pinto et al. (2018), com o método em painel System-GMM e dados de todos estados brasileiros de 2001 a 2014, analisa o componente inercial do crime, assim como os efeitos de escolaridade, renda, pobreza, desigualdade de renda e gastos com segurança pública nos homicídios dolosos. Observa efeito médio positivo do crime defasado em um período, o que também é encontrado por Teixeira (2011); Marques Jr (2014), sinalizando que o crime tem um componente inercial. Além disso, sugere que a escolaridade é capaz de reduzir a criminalidade, ao contrário da renda média, associada a coeficientes com sinais positivos. Os outros resultados indicam que a pobreza, o coeficiente de Gini e os gastos com segurança púbica não são associados a efeitos significativos na taxa de homicídios.

Barros et al. (2019)) averiguam a existência de dependência e de heterogeneidade espacial da criminalidade e a relação com o desenvolvimento econômico para todos os municípios brasileiros. Para isso, usam o método de Análise Explanatória de Dados Espaciais e a taxa de homicídio como proxy para a criminalidade. Além disso, criam um índice de desenvolvimento econômico (IDE) como proxy para o desenvolvimento municipal. Dessa forma, os autores obtêm evidências de que o IDE e a criminalidade têm concentração e dependência espacial. Apontam, ainda, que as duas variáveis são negativamente relacionadas em grande parte dos municípios, sugerindo que o desenvolvimento inibe a taxa de óbitos por agressões. Todavia, em alguns municípios, essa relação não é válida; ou seja, melhoras nos indicadores de desenvolvimento não são capazes de desestimular a criminalidade.

Finalmente, Plassa et al. (2019) investigam a distribuição espacial e os determinantes da taxa municipal de homicídios no Nordeste brasileiro com informações de 2010 a 2014. Para isso, também utilizam Análise Explanatória de Dados Espaciais, assim como estimações de modelos de defasagem espacial. As variáveis investigadas como possíveis determinantes dos homicídios são tradicionais proxies para o desenvolvimento: Índice de Gini (desigualdade), taxa de desemprego e proporção da população na extrema pobreza. Os resultados sinalizam que, quanto maiores a desigualdade 
de renda e a taxa de desemprego, mais elevada tende a ser a taxa municipal de homicídios. Porém, ao contrário do senso comum, é sinalizada uma relação inversa (negativa) entre a pobreza e a taxa de homicídios.

\section{Indices paulistas de criminalidade}

O cálculo de índices sintéticos para mensurar e caracterizar o grau de criminalidade em dado local é uma estratégia comum na literatura. Para recortes geográficos brasileiros, podem ser citados Monteiro (2009); Soares et al. (2012); Freitas et al. (2017); Cortes et al. (2018). Baseando-se nos dois últimos e considerando que nenhum analisa o estado de São de Paulo, o presente estudo calcula os aqui chamados Índices Paulistas de Criminalidade (ICrimeSP) para todos os 645 municípios do estado nos anos de 2007 a $2016^{2}$.

O cálculo desses índices é realizado segundo a equação (1). Em cada município $i$ e ano $t$ : i) multiplica-se o número de ocorrências de cada tipo de crime $j$ pela respectiva pena mínima; ii) calcula-se o somatório dos produtos anteriores para todos os crimes $j$; iii) divide-se esse somatório pela população residente; e, finalmente, iv) multiplicase o resultado por 365 (dias). A interpretação é o total de dias de reclusão per capita por crimes ocorridos no município $i$ no ano $t$.

$$
\text { ICrimeSP } P_{i t j}=\frac{\sum_{j=0}^{k}\left(v_{i t j} \sigma_{j}\right)}{\omega_{i t}} 365
$$

sendo: ICrime $S P_{i t j}$ o índice paulista de criminalidade no município $i$ no ano $t$ referente ao crime do tipo $j ; v_{i t j}$ o número de ocorrências do crime $j(j=0, \ldots, k)$ no município $i$ no ano $t ; \sigma_{j}$ a pena mínima prevista em lei para o crime $j$; e $\omega_{i t}$ a população residente (total) do município $i$ no ano $t$.

No artigo sétimo do Código Penal Brasileiro, os crimes são divididos em duas categorias: a) contra a vida; e b) contra o patrimônio (Brasil, 1940). Assim, opta-se por calcular dois índices: o Índice Paulista de Crimes Contra a Vida (ICrimeSP - Vida) e o Índice Paulista de Crimes Contra o Patrimônio (ICrimeSP - Patrimônio). Conforme é apontado no Quadro 1, ainda em consonância com o Código Penal Brasileiro, para o cálculo do ICrimeSP - Vida são considerados dois tipos de crimes: homicídio doloso e tentativa de homicídio. O ICrimeSP - Patrimônio, por sua vez, engloba furto, furto de veículo, outros furtos, roubo, latrocínio, roubo de veículo, roubo a banco e outros roubos $^{3}$.

As informações sobre crimes contra a vida são da Secretaria de Segurança Pública de São Paulo (SSP/SP) e as sobre patrimônio são da Fundação Sistema Estadual

\footnotetext{
${ }^{2}$ Período definido pela disponibilidade dos dados necessários para os exercícios econométricos discutidos mais adiante.

${ }^{3}$ Para as definições precisas e discussões para cada um dos crimes, ver: Brasil ((Brasil, 1940), (Brasil, 1984), (Brasil, 2018), (Brasil, 2019)) e Kahn ((Kahn, 2005)).
} 
de Análise de Dados (SEADE). Nos dois casos, os dados disponibilizados consolidam boletins de ocorrência (B.O.), que especificam os locais dos crimes, o que é fundamental em análises de efeitos de atributos locacionais na criminalidade. Um limitante é que não é considerado se um boletim registra mais de um objeto roubado ou óbito. Esse problema de subnotificação não invalida a utilização de índices de criminalidade para evoluções e comparações entre locais, dado ser plausivel supor que quanto mais boletins, maior a criminalidade. Ressalva-se, ainda, que a subnotificação é: i) um problema intrínseco aos dados oficiais, pois muitos crimes não são registrados; e ii) tende a ser menor nos crimes contra a vida, pois o registro de roubos e furtos é muito atrelado ao valor do bem e à confiança da vítima na polícia e justiça; já nos crimes com óbitos, a presença da polícia é obrigatória (Souza, 2003; Kume, 2004; Teixeira, $2011)$.

Guadro 1. Crimes, penas e legislações, segundo as categorias

\begin{tabular}{|c|c|c|c|}
\hline Categorias & Crimes (Tipos) & $\begin{array}{l}\text { Penas } \\
\text { (anos) }\end{array}$ & Legislações \\
\hline \multirow[t]{2}{*}{ Contra a vida } & Homicídio Doloso & 6 a 20 & $\begin{array}{l}\text { Art. } 121 \text { do CP (Decreto-Lei nº 2.848/1940); } \\
\text { Lei } n^{\circ} 13.964 / 2019\end{array}$ \\
\hline & $\begin{array}{l}\text { Tentativa de } \\
\text { Homicídio }\end{array}$ & 6 a 13,3 & $\begin{array}{l}\text { Art. 14, § único do CP (Decreto-Lei } n^{\circ} \text { 2.848/1940); } \\
\text { Lei no } 7.209 / 1984 \text {; Lei no } 13.964 / 2019\end{array}$ \\
\hline \multirow{3}{*}{$\begin{array}{l}\text { Contra o } \\
\text { patrimônio }\end{array}$} & $\begin{array}{c}\text { Furto } \\
\text { Furto de Veículo } \\
\text { Outros Furtos } \\
\text { Roubo }\end{array}$ & $\begin{array}{c}1 \text { a } 4 \\
3 \text { a } 8 \\
3 \text { a } 8 \\
4 \text { a } 10\end{array}$ & $\begin{array}{l}\text { Art. } 155 \text { do CP (Decreto-Lei nº 2.848/1940); } \\
\text { Lei } n^{\circ} 13.964 / 2019\end{array}$ \\
\hline & Latrocínio & 20 a 30 & $\begin{array}{l}\text { Art. 157, § } 3 \text { do CP (Decreto-Lei } \mathrm{n}^{\circ} \text { 2.848/1940); } \\
\text { Lei } \mathrm{n}^{\circ} 13.654 / 2018 ; \text { Lei } \mathrm{n}^{\circ} \text { 13.964/2019 }\end{array}$ \\
\hline & $\begin{array}{c}\text { Roubo de Veículo } \\
\text { Roubos a Banco } \\
\text { Outros Roubos }\end{array}$ & $\begin{array}{l}4 \text { a } 10 \\
4 \text { a } 10 \\
4 \text { a } 10\end{array}$ & $\begin{array}{l}\text { Art. } 157 \text { do CP (Decreto-Lei no } 2.848 / 1940) \\
\text { Lei nº } 13.964 / 2019\end{array}$ \\
\hline
\end{tabular}

Fontes: Brasil (1940, 1984, 2018, 2019). Elaboração própria. CP - Código Penal brasileiro.

A ponderação pelas penas também é prática usual na literatura, sendo adotadas as mínimas por muitos condenados no país não cumprirem as sentenciadas devido a vários fatores, como: progressão de regime, mutirão carcerário e audiência de custódia. Ademais, um valor entre os intervalos poderia aumentar as diferenças dos pesos em função da heterogeneidade de amplitudes entre delitos distintos (Durlauf e Nagin, 2011). Cabe pontuar, ainda, que a multiplicação pelas penas é uma forma de ponderar pelas gravidades dos crimes e, assim, pelos custos sociais. Essa ponderação também pode reduzir problemas de endogeneidade em estimações econométricas e lidar com a omissão de variáveis relevantes, que pode resultar em viés nos estimadores das variáveis de deterrence (Mustard, 2003) - elementos de intimidação sobre a decisão do transgressor de violar a lei, como as probabilidades de apreensão e de condenação e os investimentos em segurança (alterações dos custos de oportunidade).

A Tabela 1 reporta estatísticas descritivas dos ICrimeSP - Vida e ICrimeSP - Patrimô- 
nio dos municípios por recortes geográficos e os anos de 2007 e 2016 (extremos do período analisado). Na média, os dois índices são maiores nos municípios litorâneos. Isso possivelmente se deve a fatores relacionados às populações flutuantes. As casas de praia vazias são atrativas a bandidos, o que pode culminar em roubos e furtos. Já a concentração de pessoas, mesmo que sazonal, pode ser um fator que gera aumento de crimes brutais, pois a interação social é a principal motivação de crimes contra a vida (Guimaraes, 2014) e motivos fúteis são importantes determinantes dos crimes violentos, ainda mais em contextos com elevado consumo de bebidas alcoólicas (Dirk e Moura, 2017).

Tabela 1. São Paulo: estatísticas descritivas dos índices paulistas de criminalidade (ICrimeSP) dos municípios, segundo recortes geográficos (2007 e 2016)

\begin{tabular}{|c|c|c|c|c|c|c|c|c|c|}
\hline \multirow{2}{*}{$\begin{array}{c}\text { Índices / } \\
\text { Anos }\end{array}$} & \multicolumn{4}{|c|}{2007} & \multicolumn{4}{|c|}{2016} & \multirow{2}{*}{$\begin{array}{c}\Delta \% \\
07-16\end{array}$} \\
\hline & Média & $\begin{array}{l}\text { Desvio } \\
\text { Padrão }\end{array}$ & Mín. & Máx. & Média & $\begin{array}{l}\text { Desvio } \\
\text { Padrão }\end{array}$ & Mín. & Máx. & \\
\hline \multicolumn{10}{|c|}{ Estado de São Paulo } \\
\hline Vida & 0,53 & 0,49 & 0,00 & 4,33 & 0,43 & 0,41 & 0,00 & 2,55 & $-18,87$ \\
\hline Patrimônio & 21,17 & 13,73 & 0,00 & 116,10 & 20,72 & 12,93 & 1,64 & 117,40 & $-2,13$ \\
\hline \multicolumn{10}{|c|}{ Região Metropolitana } \\
\hline Vida & 0,71 & 0,25 & 0,14 & 1,15 & 0,40 & 0,14 & 0,09 & 0,80 & $-43,66$ \\
\hline Patrimônio & 30,32 & 13,70 & 11,95 & 64,15 & 37,97 & 18,63 & 8,88 & 93,36 & 25,23 \\
\hline \multicolumn{10}{|c|}{ Capital } \\
\hline Vida & 0,56 & - & - & - & 0,33 & - & - & - & $-41,07$ \\
\hline Patrimônio & 62,98 & - & - & - & 79,04 & - & - & - & 25,50 \\
\hline \multicolumn{10}{|c|}{ Litoral } \\
\hline Vida & 0,95 & 0,46 & 0,43 & 2,38 & 0,77 & 0,39 & 0,00 & 1,57 & $-18,95$ \\
\hline Patrimônio & 58,30 & 22,26 & 30,90 & 116,10 & 56,29 & 24,26 & 26,59 & 117,40 & $-3,45$ \\
\hline \multicolumn{10}{|c|}{ Interior } \\
\hline Vida & 0,51 & 0,50 & 0,00 & 4,33 & 0,42 & 0,42 & 0,00 & 2,55 & $-17,65$ \\
\hline Patrimônio & 19,56 & 11,66 & 0,00 & 74,29 & 18,61 & 9,32 & 1,64 & 66,11 & $-4,86$ \\
\hline
\end{tabular}

Fontes: SEADE e SSP/SP. Elaboração própria. $\Delta$ \% 07-16*: variações percentuais das médias de 2007 a 2016.

Observa-se que a Região Metropolitana de São Paulo (RMSP) possui médias dos índices de criminalidade superiores às médias de todo estado e que, de 2007 a 2016, a média do ICrimeSP - Patrimônio cresceu apenas nos municípios dessa região (inclusive na capital). Destaca-se, ainda, que o índice de patrimônio mínimo deixou de ser zero nos municípios do interior em 2016, o que pode ser devido à maior facilidade para registro de B.O., que passou a ser feito até pela internet. A média do ICrimeSP - Vida caiu em todos os recortes geográficos, mais acentuadamente na RMSP e capital.

As Figuras 1 e 2 apresentam as distribuições espaciais dos indices de criminalidade em 2007 e 2016. Nos crimes contra a vida, o total de municípios com maiores índices reduziu no período, em especial perto do litoral sul e no norte. Em 2007, os 
índices nas três maiores faixas se concentravam mais no sudeste do estado (RMSP e Campinas), enquanto, em 2016, os índices tenderam a ser menores e mais dispersos - apenas o litoral norte (Vale do Paraíba Paulista) manteve alguma concentração de maiores índices. Nos crimes contra o patrimônio, no geral, os municípios do leste, destacando-se os da RMSP, possuíam índices superiores aos do oeste nos dois anos. Uma possivel justificativa é a maior concentração populacional e de renda, que elevam os ganhos potenciais de práticas criminosas.

Figura 1. São Paulo: distribuição espacial do ICrimeSP - Vida nos municípios paulistas (2007 e 2016)
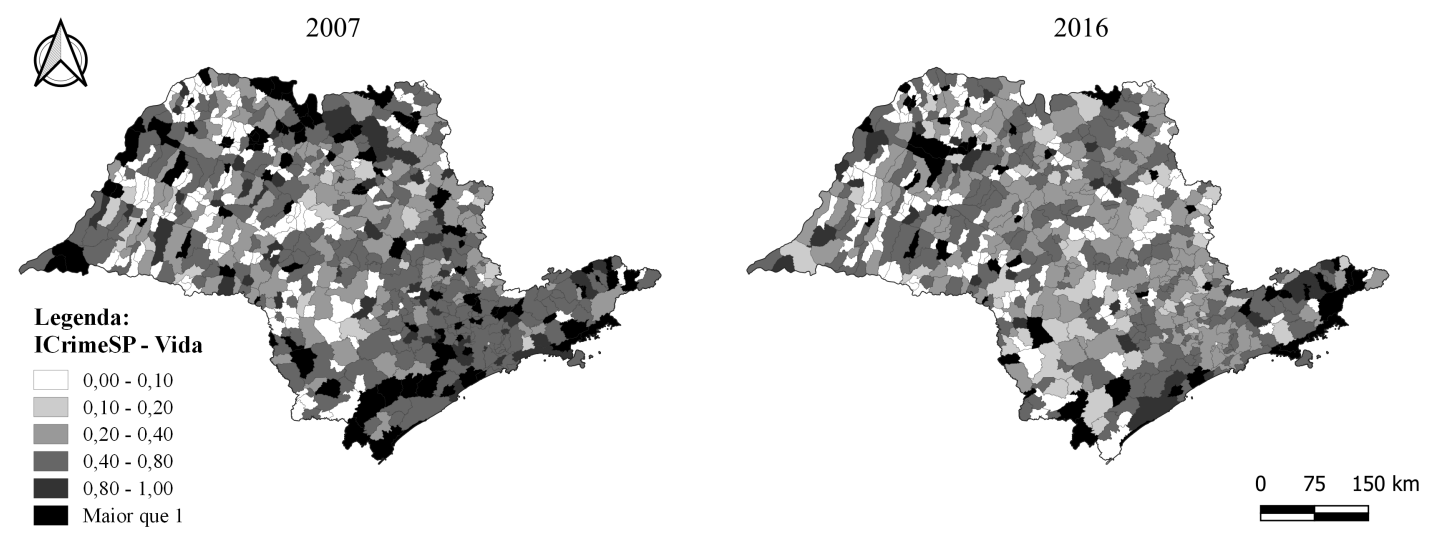

Fonte: SEADE e SSP/SP. Elaboração própria.

Figura 2. São Paulo: distribuição espacial do ICrimeSP - Patrimônio nos municípios paulistas (2007 e 2016)
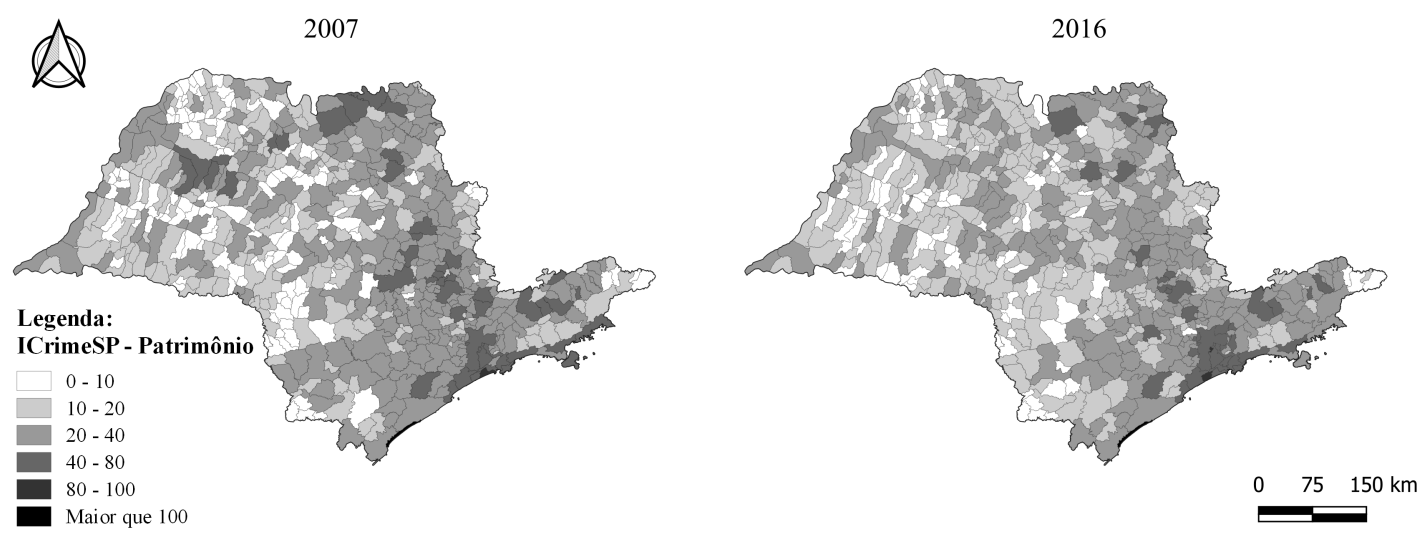

Fonte: SEADE e SSP/SP. Elaboração própria.

As reduções dos homicídios em todo o estado e, na média, a maior ocorrência desses na RMSP são fenômenos discutidos na literatura. Foge do escopo deste estudo apresentar de forma aprofundada tal debate, mas vale apontar algumas das principais justificativas: i) retirada de armas de circulação (Estatuto do Desarmamento); ii) transições demográficas (redução de jovens); iii) novas ferramentas e técnicas de gestão policial; iv) maior participação dos municípios em ações de segurança pública (por exemplo, criação de Guardas Municipais e controle da venda de bebidas alcóo- 
licas); v) domínio da facção criminosa Primeiro Comando da Capital (diminuição das disputas por territórios); v) crescimento econômico e redução do desemprego; vi) valorização salarial; vii) políticas de distribuição de renda; viii) quedas da pobreza e da desigualdade de renda; e ix) apoio de organizações sociais e comunidades aos mais pobres (Santos, 2008; Ferreira et al., 2009; Cerqueira, 2010; Hartung e Pessoa, 2010; Peres et al., 2011, 2012; Kahn, 2013; Justus et al., 2018).

\section{Estratégias empíricas e dados}

Para investigar efeitos do desenvolvimento econômico na criminalidade nos municípios de São Paulo e se esses efeitos são heterogêneos em diferentes regiões do estado, são estimados modelos em painel baseados nas equações (2) e (3) com dados dos 645 municípios paulistas de 2007 a $2016^{4}$.

$$
\begin{gathered}
Y_{i t}=\beta_{0}+\partial Y_{i, t-1}+D_{i t}^{\prime} \beta_{1}+Z_{i t} \beta_{2}+T_{t}^{\prime} \beta_{3}+\mu_{i t} \\
\mu_{i t}=\sigma_{i}+\rho_{i t}
\end{gathered}
$$

sendo: $Y_{i t}$ as variáveis dependentes do município $i$ no ano $t(t=2007, \ldots, 2016) ; \beta_{0}$ a constante; $\partial$ os coeficientes das variáveis dependentes defasadas $\left(Y_{i, t-1}\right) ; D_{i t}^{\prime}$ o vetor das variáveis explicativas de interesse para o presente estudo; $\beta_{1}$ o vetor de coeficientes destas variáveis; $Z_{i t}$ o vetor das covariadas (variáveis de controle); $\beta_{2}$ o vetor de coeficientes das covariadas; $T_{t}^{\prime}$ o vetor de dummies anuais (2007 como default) efeitos fixos temporais -; $\beta_{3}$ o vetor de coeficientes dessas dummies; $\mu_{i t}$ o erro; $\sigma_{i}$ os efeitos específicos de cada município fixos no tempo e $\sigma_{i} \sim \operatorname{IID}\left(0, \theta_{\sigma}^{2}\right)$; e $\rho_{i t}$ os choques específicos de cada município variáveis (e correlacionados) no tempo, heterocedásticos e $\rho_{i t} \sim \operatorname{IID}\left(0, \theta_{\rho}^{2}\right)$.

As variáveis dependentes $\left(Y_{i t}\right)$ são os $I C$ rime $S P^{\cup}$ Vida e ICrime $S P^{\cup}$ Patrimnio discutidos na seção anterior. Para melhor ajustamento, esses são utilizados em logaritmos neperianos (modelo log-nível). Relembrando, nos cálculos desses índices, os crimes são ponderados pelas respectivas penas mínimas (Quadro 1), o que contorna possíveis vieses nos coeficientes de variáveis de deterrences. Tal problema pode advir da omissão de regressores relevantes (Mustard, 2003). Ademais, as variáveis explicativas de interesse para o estudo (Guadro 2) têm variabilidade horizontal e longitudinal, o que é um potencial instrumento à atribuição de causalidade a efeitos estimados (Galiani et al., 2005).

As principais críticas a investigações empíricas sobre determinantes dos crimes são a omissão de variáveis explicativas relevantes e a possibilidade de simultaneidade,

\footnotetext{
${ }^{4} \mathrm{O}$ ano de 2016 é último para o qual os Îndices FIRJAN de Desenvolvimento Municipal estão disponíveis no momento de finalização deste estudo. De 2007 a 2016, é maximizada a quantidade de municípios com todos os dados disponiveis.
} 
culminando em problemas de endogeneidade (Santos e Kassouf, 2007; Marchezini e Kuwahara, 2018). Como já mencionado, a subnotificação de crimes é outro problema, em especial contra o patrimônio. Alguns trabalhos a tratam como estável no tempo e empregam métodos que assumem o erro de medição correlacionado às variáveis exógenas. Porém, o controle apenas pela heterogeneidade não observada é insuficiente para lidar com todos os problemas de endogeneidade. Pode existir causalidade reversa ou o componente do erro de medição variável no tempo ser correlacionado às variáveis explicativas consideradas nos modelos estimados (Araujo Jr e Fajnzylber, 2000; Teixeira, 2011).

Para contornar tais problemas, a opção aqui adotada é a realização de estimações em painel dinâmico por métodos de Momentos Generalizados (GMM) ${ }^{5}$. Esses incluem a variável dependente defasada $\left(Y_{i, t-1}\right)$ no hall de variáveis explicativas - o que também permite averiguar se há "inércia" nos crimes, ou seja, persistências das variáveis dependentes no tempo (Marques Jr, 2014) - e utilizam instrumentos. O Diff-GMM de Arellano e Bond (1991) instrumentaliza os regressores não exógenos em diferenças com suas defasagens em nível. Porém, se caracterizadas como um passeio aleatório, as defasagens em nível podem ser instrumentos fracos (Blundell e Bond, 1998). Tal fato é reportado e aceito em trabalhos com avaliações de determinantes do crime (Santos, 2009).

Assim, opta-se pelo System-GMM de Arellano e Bover (1995), no qual as primeiras diferenças das variáveis não exógenas são instrumentos nas estimações em níveis, sendo possivel empregar mais de uma defasagem com o intuito de aumentar a eficiência dos estimadores. Para testar a validade dos instrumentos, são empregados os testes de Sargan e Hansen. Já para confirmar a confiabilidade dos estimadores, são realizados testes de autocorrelação de primeira e segunda ordem dos resíduos em primeira diferença (Arellano e Bover, 1995; Blundell e Bond, 1998; Teixeira, 2011).

O Quadro 2 descreve as variáveis explicativas e a Tabela 2 reporta suas estatísticas descritivas. As duas variáveis explicativas de interesse para o estudo, proxies para o desenvolvimento econômico, são os Índices FIRJAN de Desenvolvimento Municipal (IFDM) nos componentes emprego-renda e educação ${ }^{6}$.

Os dois variam entre 0 e 1 , sendo que, quanto mais próximos a 1 , mais desenvolvidos são os municípios. A escolha dos dois índices permite avaliar, conforme proposto na Introdução, efeitos heterogêneos de dimensões do desenvolvimento. O índice IFDM Emprego-Renda agrega cinco variáveis: geração de emprego formal, taxa de formalização do mercado de trabalho, geração de renda, massa salarial e índice de Gini. Já o

\footnotetext{
${ }^{5}$ Ademais, é plausível presumir que os dados criminais têm características de clusters. Assim, não é possível supor que a variância do erro não observado condicional às variáveis explicativas seja constante, o que viola a hipótese de homocedasticidade. Por isso, são considerados erros-padrão por cluster (Greene, 1997; Baltagi, 2001).

${ }^{6}$ Há, ainda, o IFDM para a saúde. Porém, assim como em Oliveira (2016), também em avaliação de determinantes da criminalidade (em Pernambuco), esse não é considerado por não ter discussão na literatura que subsidia tal inclusão e por ser possivel que seu componente "mortes por causas indeterminadas" seja, pelo menos em parte, decorrente de crimes.
} 
Quadro 2. Variáveis explicativas: descrições e fontes

\begin{tabular}{|c|c|c|c|}
\hline \multicolumn{2}{|c|}{ Variável } & Descrição & Fonte \\
\hline \multirow{12}{*}{$\begin{array}{l}\text { Explicativas } \\
\text { de interesse }\end{array}$} & $\begin{array}{l}\text { IFDM } \quad \text { Emprego- } \\
\text { Renda }\end{array}$ & $\begin{array}{l}\text { Índice FIRJAN de Desenvolvimento Municipal - Di- } \\
\text { mensão Emprego e Renda }\end{array}$ & \multirow{6}{*}{ FIRJAN } \\
\hline & IFDM Educação & $\begin{array}{l}\text { Îndice FIRJAN de Desenvolvimento Municipal - Di- } \\
\text { mensão Educação }\end{array}$ & \\
\hline & $\begin{array}{l}\text { RMSP*IFDM } \\
\text { Emprego-Renda }\end{array}$ & $\begin{array}{l}\text { Interação entre a dummy RMSP e o IFDM Emprego } \\
\text { e Renda }\end{array}$ & \\
\hline & $\begin{array}{l}\text { Litoral*IFDM } \\
\text { Emprego-Renda }\end{array}$ & $\begin{array}{l}\text { Interação entre a dummy litoral e o IFDM Emprego } \\
\text { e Renda }\end{array}$ & \\
\hline & $\begin{array}{l}\text { RMSP*IFDM Edu- } \\
\text { cação }\end{array}$ & Interação entre a dummy RMSP e o IFDM Educação & \\
\hline & $\begin{array}{l}\text { Litoral*IFDM Edu- } \\
\text { cação }\end{array}$ & Interação entre a dummy litoral e o IFDM Educação & \\
\hline & Abandono EM & Taxa de abandono no Ensino Médio & \multirow{3}{*}{ INEP } \\
\hline & $\begin{array}{l}\text { RMSP*Abandono } \\
\text { EM }\end{array}$ & $\begin{array}{l}\text { Interação entre a dummy RMSP e a variável Aban- } \\
\text { dono EM }\end{array}$ & \\
\hline & $\begin{array}{l}\text { Litoral*Abandono } \\
\text { EM }\end{array}$ & $\begin{array}{l}\text { Interação entre a dummy litoral e a variável Aban- } \\
\text { dono EM }\end{array}$ & \\
\hline & IFDM Consolidado & $\begin{array}{l}\text { Îndice FIRJAN de Desenvolvimento Municipal Con- } \\
\text { solidado }\end{array}$ & \multirow{3}{*}{ FIRJAN } \\
\hline & $\begin{array}{l}\text { RMSP*IFDM Con- } \\
\text { solidado }\end{array}$ & $\begin{array}{l}\text { Interação entre a dummy RMSP e o IFDM Consoli- } \\
\text { dado }\end{array}$ & \\
\hline & $\begin{array}{l}\text { Litoral*IFDM Con- } \\
\text { solidado }\end{array}$ & $\begin{array}{l}\text { Interação entre a dummy litoral e o IFDM Consoli- } \\
\text { dado }\end{array}$ & \\
\hline \multirow{9}{*}{$\begin{array}{l}\text { Explicativas } \\
\text { de controle } \\
\text { (covariadas) }\end{array}$} & Arma de Fogo & $\begin{array}{l}\text { Número de armas de fogo apreendidas para cada mil } \\
\text { habitantes }\end{array}$ & \multirow{3}{*}{$\mathrm{SSP} / \mathrm{SP}$} \\
\hline & Entorpecentes & $\begin{array}{l}\text { Número de ocorrências por porte de entorpecentes e } \\
\text { por tráfico de entorpecentes para cada mil habitan- } \\
\text { tes }\end{array}$ & \\
\hline & $\begin{array}{l}\text { Tráfico de Entorpe- } \\
\text { centes }\end{array}$ & $\begin{array}{l}\text { Razão entre o número de ocorrências por tráfico de } \\
\text { entorpecentes e o número total de ocorrências de en- } \\
\text { torpecentes (porte + tráfico) }\end{array}$ & \\
\hline & Jovens Masculinos & $\begin{array}{l}\text { Porcentagem da população masculina entre } 15 \text { e } 24 \\
\text { anos de idade em relação à população total }\end{array}$ & \multirow{2}{*}{ SEADE } \\
\hline & Densidade & $\begin{array}{l}\text { Densidade demográfica (habitantes por quilômetro } \\
\text { quadrado) }\end{array}$ & \\
\hline & Segurança Privada & $\begin{array}{l}\text { Número de vínculos no mercado de trabalho formal } \\
\text { de acordo com a Classe } 80.11-1 \text { da CNAE } 2.0 \text { (Ati- } \\
\text { vidades de vigilância e segurança privada) por mil } \\
\text { habitantes }\end{array}$ & \multirow{2}{*}{ RAIS } \\
\hline & Segurança Pública & $\begin{array}{l}\text { Número de vínculos no mercado de trabalho formal } \\
\text { de acordo com a Classe } 84.24-8 \text { da CNAE } 2.0 \text { (Segu- } \\
\text { rança e ordem pública) por mil habitantes }\end{array}$ & \\
\hline & Detenção - Vida & $\begin{array}{l}\text { Razão entre o número de prisões no município e o } \\
\text { número de ocorrências de crimes contra a vida }\end{array}$ & \multirow{2}{*}{$\begin{array}{l}\text { SEADE } \\
\text { e SSP/SP }\end{array}$} \\
\hline & $\begin{array}{l}\text { Detenção } \\
\text { trimônio }\end{array}$ & $\begin{array}{l}\text { Razão entre o número de prisões no município e o } \\
\text { número de ocorrências de crimes contra o patrimô- } \\
\text { nio }\end{array}$ & \\
\hline
\end{tabular}

Fontes: FIRJAN, INEP, RAIS, SEADE e SSP/SP. Observações: FIRJAN - Federação das Indústrias do Estado do Rio de Janeiro; INEP - Instituto Nacional de Estudos e Pesquisas Educacionais Anísio Teixeira; RAIS - Relação Anual de Informações Sociais; SEADE - Fundação Sistema Estadual de Análise de Dados; SSP/SP - Secretaria de Segurança Pública do Estado de São Paulo. 
Tabela 2. São Paulo: estatísticas descritivas das variáveis explicativas (2007 e 2016)

\begin{tabular}{|c|c|c|c|c|c|c|c|c|}
\hline \multirow{2}{*}{ Variáveis } & \multicolumn{4}{|c|}{2007} & \multicolumn{4}{|c|}{2016} \\
\hline & Média & $\begin{array}{l}\text { Desvio- } \\
\text { Padrão }\end{array}$ & Mín. & Máx. & Média & $\begin{array}{l}\text { Desvio- } \\
\text { Padrão }\end{array}$ & Mín. & Máx. \\
\hline IFDM Emprego-Renda & 0,62 & 0,13 & 0,23 & 0,95 & 0,53 & 0,12 & 0,24 & 0,79 \\
\hline IFDM Educação & 0,81 & 0,05 & 0,65 & 0,97 & 0,93 & 0,04 & 0,78 & 1,00 \\
\hline IFDM Consolidado & 0,74 & 0,07 & 0,56 & 0,91 & 0,76 & 0,06 & 0,55 & 0,90 \\
\hline Abandono EM & 6,23 & 5,07 & 0,00 & 25 & 3,16 & 2,61 & 0,00 & 14,50 \\
\hline Arma de Fogo & 0,63 & 0,51 & 0,00 & 3,67 & 0,50 & 0,49 & 0,00 & 4,88 \\
\hline Entorpecentes & 1,20 & 1,24 & 0,00 & 15 & 2,30 & 1,80 & 0,00 & 18,67 \\
\hline Tráfico de Entorpecentes & 0,42 & 0,27 & 0,00 & 1,00 & 0,46 & 0,25 & 0,00 & 1,00 \\
\hline Jovens Masculinos & 9,05 & 0,95 & 6,82 & 18,83 & 8,31 & 1,37 & 5,76 & 24,96 \\
\hline Densidade & 291,50 & $1.160,00$ & 3,79 & $12.341,00$ & 320,60 & $1.258,00$ & 3,78 & $13.161,00$ \\
\hline Segurança Privada & 1,01 & 10,08 & 0,00 & 223,21 & 0,49 & 2,90 & 0,00 & 48,55 \\
\hline Segurança Pública & 0,02 & 0,32 & 0,00 & 8,06 & 0,01 & 0,31 & 0,00 & 7,57 \\
\hline Detenção - Vida & 12,13 & 13,18 & 0,00 & 177,00 & 27,99 & 29,91 & 0,00 & 262,00 \\
\hline Detenção - Patrimônio & 0,11 & 0,12 & 0,00 & 2,00 & 0,20 & 0,17 & 0,00 & 2,10 \\
\hline
\end{tabular}

Fontes: FIRJAN, INEP, RAIS, SEADE e SSP/SP. Elaboração própria.

indice IFDM Educação é composto por seis variáveis: atendimento à educação infantil, abandono no ensino fundamental, distorção idade-série no ensino fundamental, docentes com ensino superior no ensino fundamental, média de horas-aula diárias no ensino fundamental e resultado no Índice de Desenvolvimento da Educação Básica (IDEB) no ensino fundamental (FIRJAN, 2018) ${ }^{7}$.

Quanto ao IFDM Emprego-Renda, vale apontar que o já comentado modelo de Becker ((Becker, 1968)) considera que os indivíduos condicionam suas decisões a fatores que elevam a utilidade de cometer um crime. Logo, o agente decide ou não ingressar na vida criminosa pela comparação racional dos ganhos e das perdas entre práticas ilícitas e o mercado de trabalho legal. É plausível esperar, então, que municípios com melhores indicadores de emprego e renda tenham mais e melhores oportunidades de trabalho formal, o que eleva o custo de oportunidade de atos criminosos. Ademais, municípios com baixos desenvolvimentos também tendem a ter maiores desigualdades de renda (Barros e Gomes, 2008) e de oportunidades, o que potencializa as vulnerabilidades sociais, estimulando a criminalidade.

Assim, é plausivel esperar um efeito negativo do emprego-renda na criminalidade

\footnotetext{
${ }^{7}$ Para mais detalhes sobre os cálculos dos índices FIRJAN, conferir: FIRJAN (2018).
} 
(Oliveira, 2016). Porém, também é coerente aventar a possibilidade de que, em municípios mais desenvolvidos, os crimes contra o patrimônio sejam maiores devido aos maiores ganhos potenciais dos criminosos (Santos e Kassouf, 2008; Kahn, 2013). Ou seja, pode ser constatado um efeito positivo do emprego-renda, o que torna interessante a comparação entre os efeitos nos crimes contra a vida e contra o patrimônio. Avaliam-se, ainda, efeitos temporais, pois pode existir um intervalo entre os momentos em que o indivíduo se defronta com o desemprego ou com baixos salários e o de ingresso no mercado ilícito. Por isso, utiliza-se o IFDM Emprego-Renda em nível e defasado em um período.

A relação entre desenvolvimento na dimensão do emprego-renda e criminalidade pode ser mais complexa devido à potencial endogeneidade (Kume, 2004; Pinto et al., 2018). Intuitivamente, por um lado, niveis maiores de emprego e renda podem reduzir crimes; por outro lado, piores indicadores de criminalidade podem inibir a economia formal local - por exemplo, desincentivando a ida de novas empresas para os municípios. Assim, a oferta de trabalho e os salários são negativamente afetados e, com isso, o grau de criminalidade pode aumentar. Para contornar tal problema, opta-se por empregar o próprio IFDM Emprego-Renda defasado em quatro períodos como instrumento, pois se espera que, em quatro anos, os efeitos que geram endogeneidade da variável em questão já tenham se dissipado.

Quanto ao IFDM Educação, é pressuposto que melhores condições educacionais aumentam o custo de oportunidade do crime, visto que o indivíduo poderá conseguir maiores ganhos no mercado lícito no futuro (Becker, 1968). Ademais, quanto menor o abandono escolar - um dos componentes do índice -, menos jovens expostos e, consequentemente, menor a probabilidade de eles ingressarem na "vida do crime". Pelo lado das vítimas potenciais, maiores níveis de instrução tendem a fazer com que elas obtenham maiores rendimentos e acesso a informações, o que lhes garante maior capacidade de prevenção contra os crimes (Kume, 2004; Cerqueira e Coelho, 2015; Silva et al., 2019).

Santos e Kassouf (2008) mostram que os crimes contra a vida são mais frequentes em periferias, onde se concentram as pessoas socialmente mais vulneráveis; enquanto os crimes contra o patrimônio predominam em localidades com maiores níveis de renda e de acesso à educação e a outros serviços básicos. Assim, espera-se que o efeito da educação seja maior nos crimes "desqualificados" vis-à-vis os crimes "qualificados"8. Outra justificativa para um possível efeito estimado relativamente maior do IFDM Educação nos crimes contra a vida é o fato de esses crimes estarem mais associados à tensão e desorganização social, que são relacionadas a questões morais influenciadas pelo grau de instrução.

Considerando Teixeira (2011); Duenhas et al. (2014), é plausível cogitar que tam-

\footnotetext{
${ }^{8}$ Os crimes "desqualificados" são aqueles que exigem poucas habilidades dos infratores, como homicídios e tentativas de homicídio; já os "qualificados" requerem maiores habilidades, como roubos e furtos (Santos e Kassouf, 2008).
} 
bém exista endogeneidade na proxy de desenvolvimento pela educação - enquanto um nivel educacional maior pode reduzir os crimes, maiores níveis de criminalidade podem afetar o desempenho escolar. Assim, seguindo a mesma lógica do emprego e renda, procura-se contornar o problema com o próprio IFDM Educação defasado em quatro períodos como instrumento. Já para avaliar possiveis efeitos distintos no tempo, são estimados modelos com o índice de educação como regressor defasado em um período. Conforme Fajnzylber et al. (1998); Teixeira (2011), depois de um ano de abandono da escola e sem obter boas oportunidades de trabalho formal, aumenta-se a probabilidade de um jovem cometer crimes.

Vale ressaltar que são realizadas estimações adicionais em que a proxy para a educação é a taxa de abandono escolar no ensino médio - nível escolar que contempla parte da faixa etária com maior probabilidade de ingressar na "vida do crime" (jovens). A inserção da variável abandono (em nível e defasada em um ano) cumpre o papel de sinalizar se somente esse aspecto influencia a criminalidade (ou seja, uma proporção maior dos jovens fora das escolas) ou se essa é afetada pela condição geral da educação municipal sintetizada pelas variáveis de ensino fundamental que compõem o IFDM Educação, o que seria um indicativo da possibilidade de a educação básica efetivamente se consolidar como uma das principais travas morais (juntamente com religião e família) à não migração para atividades criminosas (Becker, 1968; Shikida, 2020). Assim, implicitamente, o IFDM Educação captaria os efeitos de maiores noções de moralidade e civilidade e de maiores custos psíquicos de desobedecer às leis que decorrem da educação (Lochner, 2011; Becker e Kassouf, 2017).

Outra estimação adicional consiste na inserção do IFDM Consolidado (em nível) ao invés das suas dimensões. Se os resultados forem distintos entre as dimensões para um mesmo tipo de crime, o índice agregado tem o intuito de apontar se prevalece o efeito do emprego-renda ou da educação.

Como na seção anterior foi observado que os índices de criminalidade no estado de São Paulo não seguem a mesma tendência nos diferentes recortes geográficos analisados (em magnitudes e até mesmo no sentido), também é interessante investigar se os índices de desenvolvimento geram efeitos heterogêneos segundo localidades do estado. Para isso, são consideradas interações entre os índices de desenvolvimento (e a taxa de abandono) e as dummies municípios da RMSP e do litoral (Quadro 2) - assim, os municípios do interior são a base de comparação. Adota-se o mesmo procedimento que o dos índices sem interações para lidar com a endogeneidade (instrumentalização por defasagens).

Considerando a Tabela 3, vale destacar que, na média, os índices de desenvolvimento entre os recortes geográficos se diferenciam pouco, principalmente em 2016 o que sugere convergência do nível de desenvolvimento municipal no tempo. Nota-se, ainda, que as médias do IFDM Emprego-Renda nos três recortes caíram de 2007 a 2016 e as do IFDM Educação aumentaram. Assim, houve aumento médio do desenvolvimento na dimensão educação, mas piora na dimensão emprego-renda. 
Tabela 3. São Paulo: médias dos índices FIRJAN de desenvolvimento municipal selecionados (IFDM Emprego-Renda e IFDM Educação), segundo recortes geográficos (2007 e 2016)

\begin{tabular}{|c|c|c|c|c|c|c|c|c|c|}
\hline \multirow{2}{*}{ Variáveis } & \multicolumn{3}{|c|}{ RMSP } & \multicolumn{3}{|c|}{ Litoral } & \multicolumn{3}{|c|}{ Interior } \\
\hline & 2007 & 2016 & $\begin{array}{l}\Delta 2016- \\
2007\end{array}$ & 2007 & 2016 & $\begin{array}{l}\Delta 2016- \\
2007\end{array}$ & 2007 & 2016 & $\begin{array}{l}\Delta 2016- \\
2007\end{array}$ \\
\hline IFDM Emprego-Renda & 0,67 & 0,56 & $-0,11$ & 0,60 & 0,56 & $-0,04$ & 0,62 & 0,52 & $-0,10$ \\
\hline IFDM Educação & 0,77 & 0,92 & 0,15 & 0,78 & 0,91 & 0,13 & 0,82 & 0,93 & 0,11 \\
\hline
\end{tabular}

Fontes: FIRJAN. Elaboração própria. $\Delta$ 2016-2007: indicador em 2016 menos o indicador em 2007.

As Figuras 3 e 4 mostram as distribuições espaciais dos índices de desenvolvimento em 2007 e 2016. Em 2007, grande quantidade de municípios compunha a faixa mais alta na dimensão emprego-renda; por outro lado, em 2016, nenhum município estava na faixa, provavelmente em razão da crise econômica do país pós-2014. Ademais, na faixa mais baixa, concentram-se os municípios do oeste e do litoral sul. Na dimensão educação, nota-se que, em 2007, grande parte dos municípios que estavam na faixa moderada se localizavam na região litorânea e na RMSP, com destaque também para o Vale do Paraíba Paulista. Já em 2016, quase todos os municípios se concentravam na faixa mais elevada ${ }^{9}$.

Figura 3. São Paulo: a distribuição espacial do IFDM Emprego-Renda nos municípios paulistas (2007 e 2016)
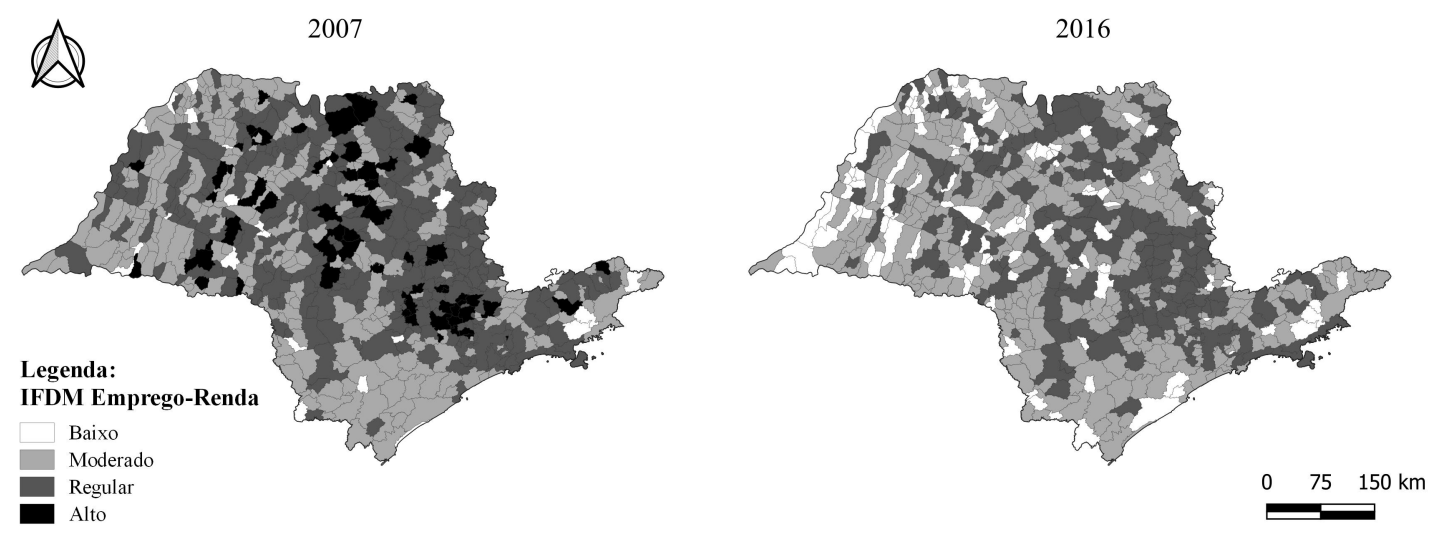

Fonte: FIRJAN. Elaboração própria.

Respeitando a disponibilidade de dados, as covariadas foram escolhidas por serem proxies para fatores defendidos na literatura como possiveis determinantes de crimes. O tráfico de entorpecentes é justificado por Lima et al. (2005); Santos e Kassouf (2007); Justus et al. (2018) advogarem que o "mercado do tráfico" não se limita à produção,

\footnotetext{
${ }^{9}$ Não há dados disponíveis do IFDM Educação para o município de Guaiçara em nenhum dos dois $\operatorname{anos}(2007$ e 2016).
} 
Figura 4. São Paulo: a distribuição espacial do IFDM Educação nos municípios paulistas (2007 e 2016)
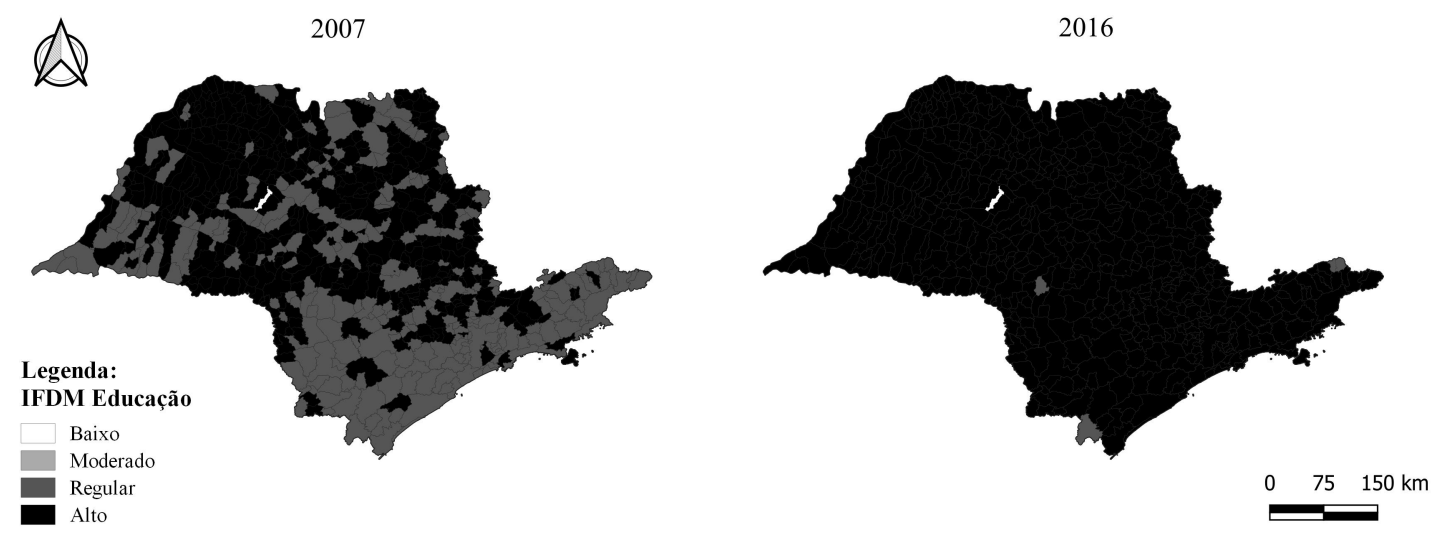

Fonte: FIRJAN. Elaboração própria.

comercialização e distribuição de drogas, mas também envolve práticas de violência física para a manutenção, inclusive entre grandes facções concorrentes. Os mesmos trabalhos sinalizam que, sob o efeito de drogas ilícitas, o usuário pode cometer crimes violentos ou, para manter o vício, recorrer a roubos e furtos. Por isso, são controladas as variáveis entorpecentes e tráfico de entorpecentes. Devido a suas características intrínsecas, no System-GMM, são consideradas como endógenas e, para lidar com isso, são usadas suas defasagens em um período.

Os efeitos da arma de fogo podem ser antagônicos. Por um lado, argumenta-se que o aumento da quantidade de armas nas mãos da população pode diminuir os crimes devido a um efeito dissuasão - criminosos atribuem maior custo aos crimes em função da maior probabilidade de a vítima estar armada (Moody, 2010). Por outro lado, evidências da literatura sinalizam que o aumento do estoque de armas eleva a probabilidade de conflitos culminarem em mortes (Hartung e Pessoa, 2010; Peres et al., 2012). Jorge (2020) ressalta que avaliações da relação entre armas e criminalidade carecem de um diagnóstico da disponibilidade de armas no local, o que não é trivial, principalmente devido ao mercado informal (armas não registradas ou de uso criminal). Dentre as possibilidades de proxies, o autor destaca o número de armas apreendidas, em especial para análises em painel com controle de efeitos fixos para lidar com diferenças de produtividade policial e do grau de prioridade dado à apreensão de armas em cada local. O presente estudo segue essas recomendações. Ressalta-se que a variável arma de fogo pode ter um componente endógeno, sendo utilizada a defasagem em um ano como instrumento, também de acordo com a literatura (Marchezini e Kuwahara, 2018).

Como variáveis de deterrence, além da proxy proposta por Marchezini e Kuwahara (2018), i.e., a taxa de detenção, são empregadas: segurança privada e segurança pública. A detenção busca controlar a eficiência policial, sinalizando a probabilidade de apreensão do infrator. Assim, quanto mais elevada, maior o custo de oportunidade 
de práticas criminosas. Já as outras duas variáveis são proxies para o efetivo policial e de agentes de segurança em geral. Como pode existir um efeito endógeno nessas variáveis, são consideradas suas defasagens em um período como instrumento. Vale ressaltar que todos os regressores são embasados pela literatura econômica do crime, que os apontam como possiveis determinantes da criminalidade. A literatura sugere, ainda, que seus efeitos tendem a não ser muito diferentes entre os crimes contra a vida e contra o patrimônio, mesmo com motivações distintas. Assim, as covariadas são as mesmas para as duas categorias de crimes consideradas. A única mudança é justamente na detenção, que é considerada especificamente para a categoria em análise.

O controle por jovens masculinos é fundamentado por Araujo Jr e Fajnzylber (2000). Esses sinalizam que quanto maior a participação de homens jovens na população de uma localidade, maiores são os roubos (à mão armada, inclusive) e os crimes contra as pessoas. Já para justificar o controle pela variável densidade, deve-se apontar que uma maior concentração de pessoas pode ser benéfica aos criminosos, pois podem escolher melhor as vítimas nos crimes contra o patrimônio, além de ser mais difícil a identificação e mais fácil a troca de informação, a organização da prática criminosa e a fuga (Glaeser et al., 1992; Oliveira, 2016; Pinto et al., 2018; Becker e Kassouf, 2017).

\section{Análises dos resultados}

A seguir, são discutidos os resultados das regressões. Inicialmente, deve-se apontar a estimação de dez especificações para cumprir os objetivos propostos e averiguar a robustez dos resultados frente a possiveis correlações entre as variáveis de interesse e a endogeneidade. Em todas as especificações, são inseridas as covariadas e dummies anuais. Nas especificações I e II, são consideradas somente as variáveis de desenvolvimento pela dimensão emprego-renda (IFDM Emprego-Renda, RMSP*IFDM Emprego-Renda e Litoral*IFDM Emprego-Renda), respectivamente, em níveis e defasadas. Nas III e $I V$, são inseridas as variáveis de desenvolvimento apenas na dimensão educação (IFDM Educação, RMSP*IFDM Educação e Litoral*IFDM Educação), respectivamente, em níveis e defasadas.

Nas especificações $V$ e VI, todas as variáveis relativas aos IFDM Emprego-Renda e Educação são consideradas, respectivamente, em níveis e defasadas. Já a VII considera, para fins de robustez, as variáveis de desenvolvimento pela dimensão educação defasadas e as de emprego-renda em níveis. Nas VIII e $I X$, as variáveis de desenvolvimento pela educação são substituídas pela taxa de abandono no ensino médio (Abandono EM, RMSP*Abandono EM e Litoral*Abandono EM), respectivamente, em níveis e defasadas. Por fim, a X considera as variáveis relativas ao índice de desenvolvimento agregado (IFDM Consolidado, RMSP*IFDM Consolidado e Litoral*IFDM Consolidado) em nível.

As Tabelas 4 e 5 mostram, respectivamente, os resultados para o ICrimeSP - Vida 
e o ICrimeSP - Patrimônio ${ }^{10}$. O primeiro destaque é que, em quase todas as especificações (exceto a $X$ da Tabela 3), os coeficientes dos índices de criminalidade defasados são positivos e significativos. Assim, esses corroboram a hipótese de existência de efeito inercial da criminalidade; ou seja, não é refutada a possibilidade de que um local com alta criminalidade tenha tendência de crescimento dessa devido a prováveis efeitos de aprendizagem (learning-by-doing) para atos criminosos e do menor custo moral das pessoas. Outra possível explicação é que criminosos reincidentes têm maior propensão a cometer delitos do que indivíduos que ainda não ingressaram na "vida do crime”. Assim, os custos marginais de planejamento e execução dos crimes tendem a ser menores a cada ato cometido, gerando ganhos de escala e efeito inercial se os criminosos permanecem no mesmo local. Por fim, o resultado também pode ser influenciado pelo fato de que locais mais violentos acabam elevando seu efetivo policial, mas apenas após algum tempo, pois é necessário fazer concurso público e treinar os aprovados antes de entrarem em atividade. Tal evidência corrobora outras existentes na literatura para distintos locais do Brasil (Kume, 2004; Teixeira, 2011; Marques Jr, 2014; Duenhas et al., 2014).

Para o ICrimeSP - Vida (Tabela 4), os coeficientes do IFDM Emprego-Renda em nivel são negativos e significativos em todas as especificações (I, V, VII, VIII e IX). Assim, a despeito de alguns indícios de relação positiva com amostras, métodos e proxies diferentes (Fajnzylber et al., 1998; Kume, 2004; Lima et al., 2005; Santos e Kassouf, 2008; Theodoro, 2011; Marques Jr, 2014; Oliveira, 2016), os resultados deste estudo sinalizam que melhoras na dimensão emprego-renda do desenvolvimento são benéficas à redução de crimes contra a vida nos municípios paulistas. Uma possível explicação é o aumento do custo de oportunidade do ingresso em atividades ilícitas devido à elevação dos ganhos potenciais no mercado de trabalho formal (Becker, 1968). A significância em nível e a não significância em especificações com a variável defasada (II e VI) sugerem que não existe um lag temporal para pioras no índice de empregorenda estimularem os crimes contra a vida. Ademais, os resultados não são robustos para inferir efeitos heterogêneos espaciais, dado que, na maioria das especificações em que são consideradas as interações RMSP*IFDM Emprego-Renda e Interior*IFDM Emprego-Renda, os coeficientes estimados associados a elas não são significativos.

\footnotetext{
${ }^{10}$ Os resultados das dummies anuais não são reportados e analisados para não fugir do objetivo do estudo e para respeitar o limite de espaço da revista. Esses podem ser disponibilizados pelos autores. O painel é balanceado. As estimações (System-GMM) são por Two-Step, sendo controlado o excesso de instrumentos pelo comando collapse nos modelos da Tabela 4. Os testes de Autocorrelação de Segunda Ordem, Sargan, Hansen e Difference-in-Hansen sinalizam, no geral, consistência dos estimadores e, assim, validade dos instrumentos.
} 


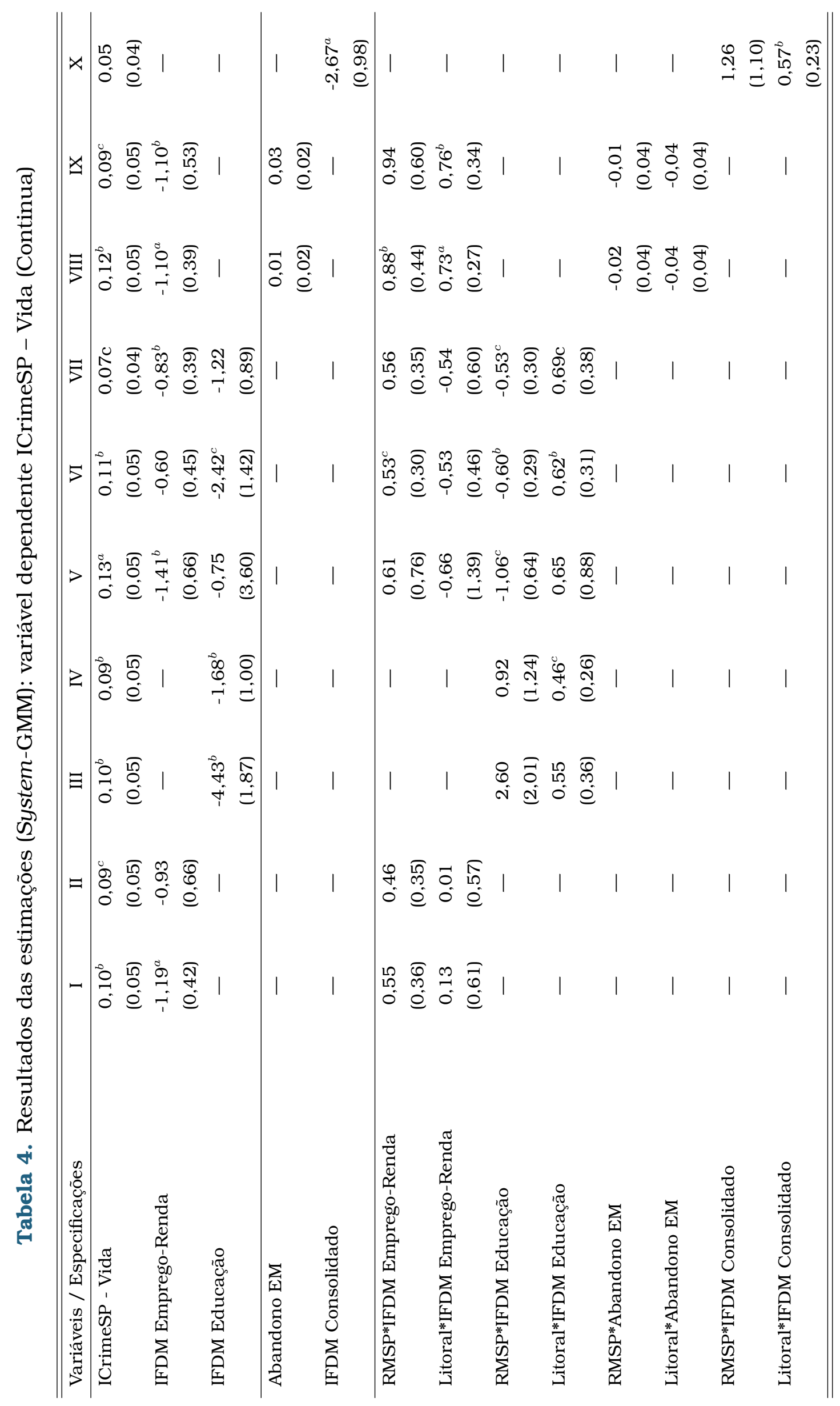




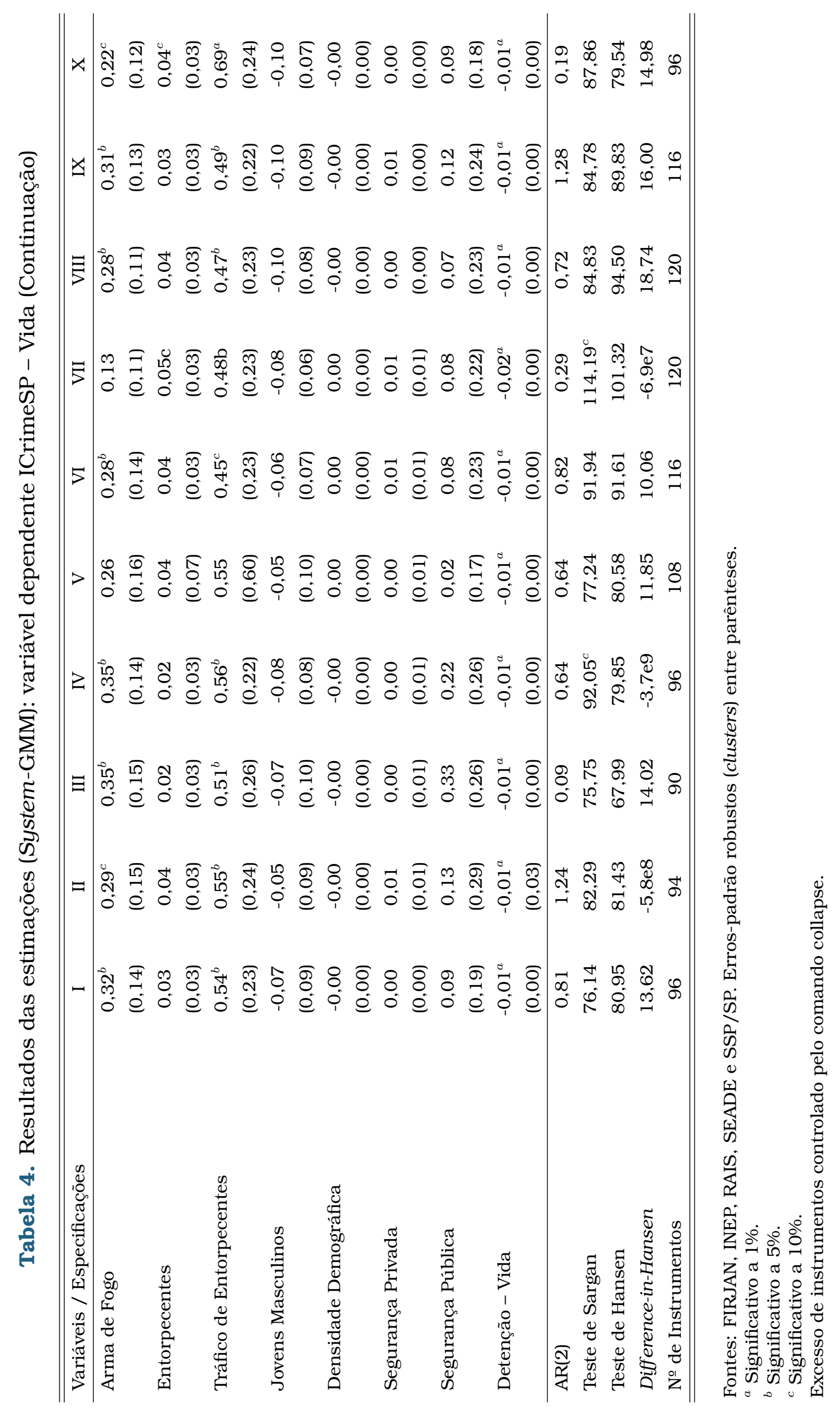




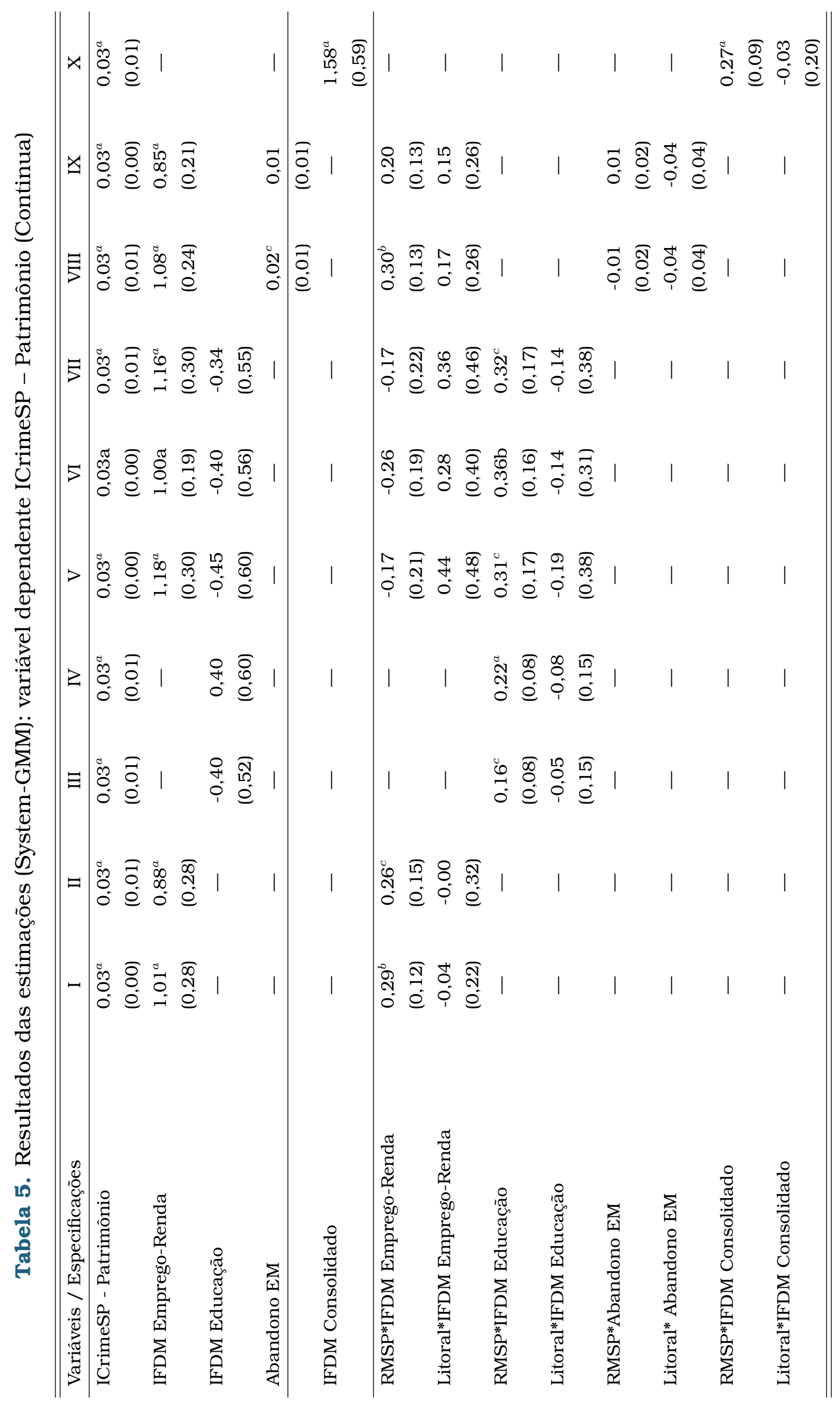




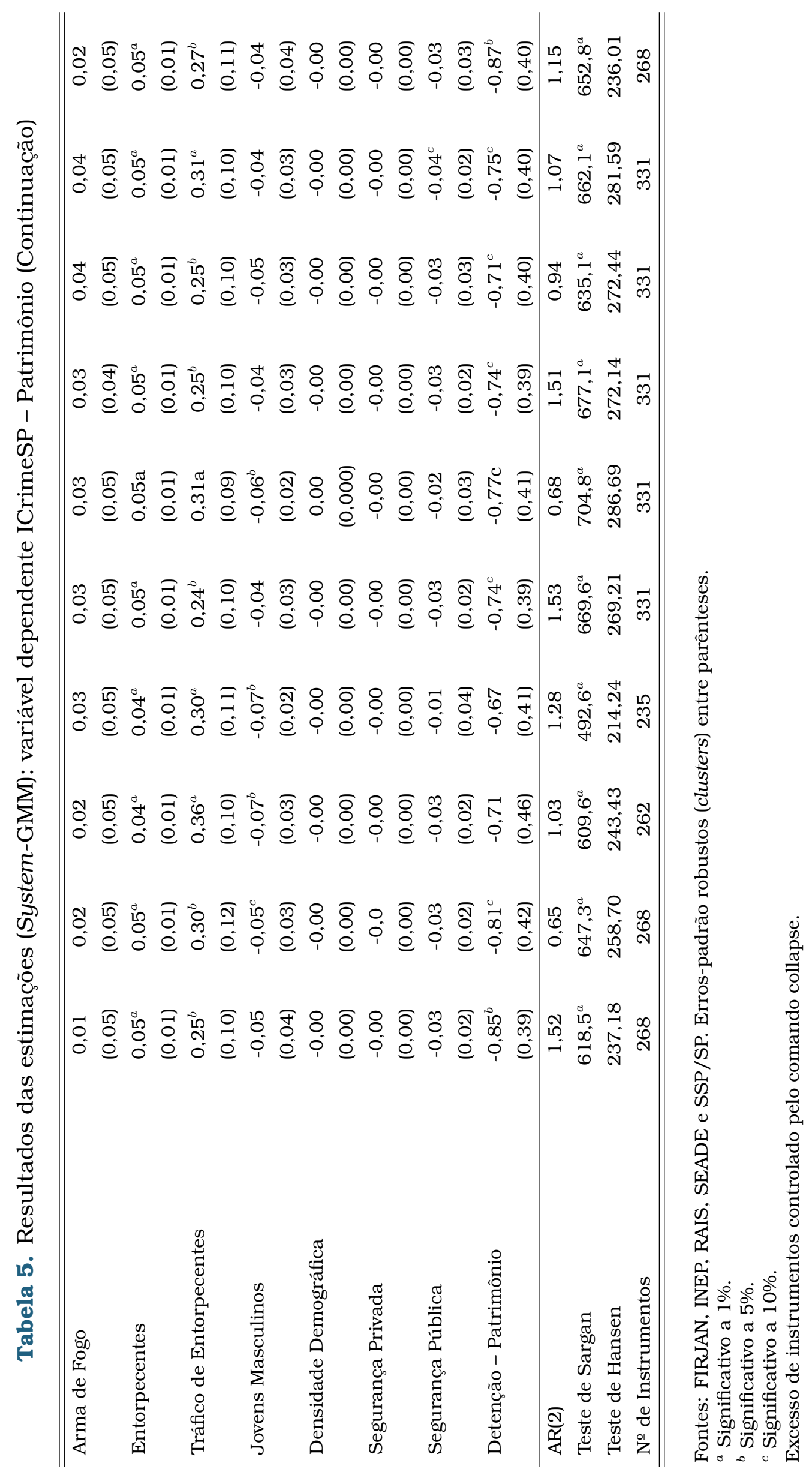


No ICrimeSP - Patrimônio (Tabela 5), os coeficientes do IFDM Emprego-Renda, em nível e defasado, são positivos e significativos em todas as especificações. Tal resultado pode ser decorrência da renda média alta dos municípios paulistas, dado que a média salarial de São Paulo é superior à dos outros estados (Silva et al., 2020), e é coerente a Gomes et al. (2014), no qual é sugerido que locais com maiores níveis de renda, mesmo com custos de oportunidade mais elevados, tendem a ter mais crimes contra o patrimônio, pois atraem os criminosos ao elevarem os ganhos potenciais. Assim, o benefício líquido pode ser positivo mesmo com maior probabilidade de captura, aqui controlada pelas variáveis segurança privada, segurança pública e detenção - patrimônio. As evidências de outros trabalhos também reforçam a consistência do resultado, como: Theodoro (2011); Oliveira e Johnston (2017); Pinto et al. (2018); Souza (2019). Cabe destacar que não há robustez para inferir efeitos heterogêneos espaciais - em várias especificações com as interações RMSP*IFDM Emprego-Renda e Interior*IFDM Emprego-Renda, seus coeficientes não são significativos.

No caso do IFDM Educação (em nível e defasado), os coeficientes estimados são negativos e significativos nos crimes contra a vida (Tabela 4). As exceções de significância são as especificações $V$ e VII. Contudo, como já apontado, isso pode advir de correlação com a variável de emprego-renda, dado que as duas dimensões são inseridas nessas especificações. A significância do índice defasado (especificações $I V$ e $V I)$ sugere que o efeito do desenvolvimento educacional nos crimes contra a vida tem um componente endógeno e que um ano é suficiente para que melhoras educacionais reduzam tal crime. Becker e Kassouf (2017), tanto por meio de uma revisão da literatura empírica como por meio de resultados próprios (painel dinâmico com dados dos estados brasileiros e gasto público com educação como proxy), também sinalizam que o impacto total da educação nos homicídios não é imediato.

Já a não significância do abandono escolar no ensino médio sugere que o impacto do IFDM Educação nos crimes contra a vida não decorre de uma maior parcela de jovens fora das escolas, mas provavelmente de uma condição geral que faz com que a educação, ao resultar em maiores noções de moralidade e civilidade e custos psíquicos de desobedecer às leis, seja efetivamente uma trava moral a tais crimes (Becker, 1968; Lochner, 2011; Shikida, 2020; Becker e Kassouf, 2017).

Nos crimes contra o patrimônio (Tabela 5), os coeficientes associados ao IFDM Educação não são significativos. Portanto, na média, maior desenvolvimento pela dimensão educação reduz crimes contra a vida, mas não tem efeito médio nos crimes contra o patrimônio. Uma possivel justificativa para tais evidências, fundamentandose em Goldstein (1985); Santos e Kassouf (2008), é que os indivíduos com menores escolaridades tendem a buscar menos os crimes "qualificados", como roubos e furtos (crimes contra o patrimônio) e mais os crimes "desqualificados" (aqueles que exigem poucas habilidades dos infratores). Assim, podem entrar em grandes facções criminosas e se envolverem em práticas, como o tráfico de drogas, que são mais violentas e mais relacionadas a crimes contra a vida. 
Considerando as interações entre as dummies locacionais e os índices de desenvolvimento, há robustez apenas para aventar um efeito potencializador nos crimes contra o patrimônio à dimensão de educação nos municípios da RMSP comparativamente aos do interior - coeficientes positivos e significativos da interação RMSP*IFDM Educação. Tal efeito decorre da condição geral da educação municipal e não do maior abandono escolar de jovens - que, ao saírem das escolas, podem ingressar no crime em busca de oportunidades superiores do que as oferecidas no mercado de trabalho formal para melhorar as condições de vida. Isso porque não é significativo o coeficiente da interação RMSP*Abandono EM. Como já apontado, no ICrimeSP - Vida (Tabela 4), o efeito do IFDM Emprego-Renda em nível é positivo e o efeito do IFDM Educação em nivel é negativo. Esse efeito negativo prevalece ao considerar o IFDM Consolidado em nível, que agrega as duas dimensões (e a de saúde). Isso porque, na especificação $X$, o coeficiente do índice consolidado é negativo e significativo. Nota-se, ainda, um efeito potencializador do desenvolvimento geral nos crimes contra a vida no litoral comparativamente ao interior - coeficiente positivo e significativo associado à interação Litoral*IFDM Consolidado.

No ICrimeSP - Patrimônio (Tabela 5), o efeito positivo associado ao desenvolvimento geral em nivel (especificação $X$ ), dada a não observância de efeito para a dimensão educação (coeficientes não significativos), é coerente ao efeito positivo (coeficientes significativos) para o desenvolvimento pela dimensão emprego-renda (em nível). Ademais, há um efeito potencializador do desenvolvimento geral nos crimes contra o patrimônio nos municípios da região metropolitana comparativamente aos do interior coeficiente positivo e significativo associado à interação RMSP*IFDM Consolidado.

Portanto, em sintese, os resultados aqui obtidos não permitem refutar que o desenvolvimento pela dimensão emprego-renda afeta positivamente a incidência de crimes contra o patrimônio (Tabela 5). Portanto, os resultados estão de acordo com o modelo de Becker (1968) e com a literatura econômica do crime, que mostra evidências consistentes às deste estudo, justificando-as pela maior atratividade a criminosos conforme o local se desenvolve, devido a maiores benefícios líquidos (Theodoro, 2011; Gomes et al., 2014; Oliveira e Johnston, 2017; Pinto et al., 2018; Souza, 2019). Intuitivamente, em municípios mais desenvolvidos, os individuos tendem a ter mais e melhores (mais valiosos) bens para serem roubados ou furtados, atraindo criminosos. Em contrapartida, o efeito do emprego-renda nos crimes contra a vida é negativo (Tabela 4). Ou seja, tais crimes tendem a reduzir com o desenvolvimento. Com amostras, métodos e proxies diferentes, é comum a literatura apontar uma relação negativa entre desenvolvimento e homicídio (Shikida, 2008; Plassa et al., 2019).

Além disso, os resultados não refutam a hipótese de o desenvolvimento pela dimensão educação reduzir crimes contra a vida (Tabela 4). Ressalva-se, ainda, que as diferenças dos resultados entre as duas proxies para dimensões do desenvolvimento nos dois tipos de crimes também são consistentes com evidências e discussões da literatura, decorrendo possivelmente das distintas motivações para cada crime. Roubos 
e furtos estão mais atrelados a questões de cunho econômico; já o homicídio à tensão e desorganização social (Santos e Kassouf, 2008; Kahn, 2013; Gomes et al., 2014).

Em relação aos resultados das covariadas, é interessante apontar breves destaques. As variáveis entorpecentes e tráfico de entorpecentes são associadas a coeficientes positivos e significativos nos crimes contra o patrimônio e, no caso da última variável, também nos crimes contra a vida (exceto na especificação $V$ ). Assim, é sugerido que as ocorrências de portes de entorpecentes afetam roubos, furtos e latrocínios, em especial quanto maior a participação do tráfico nessas ocorrências. Por outro lado, apenas o tráfico possui efeito nos crimes de agressão efetiva ou tentativa. Trata-se, então, de evidências favoráveis à hipótese de que o tráfico de drogas gera diferentes impactos prejudiciais à sociedade. Tal discussão é de suma importância em São Paulo, pois tal prática criminosa é comandada por grandes e poderosas facções, como o Primeiro Comando da Capital (PCC). Essas facções tendem a empregar outras ações ilícitas, como violência física, corrupção e aliciamento de menores, para minar a concorrência e, assim, permanecer no poder. Por outro lado, se o aumento das ocorrências de tráfico decorrer de ações deliberadas da justiça e polícia, os resultados sinalizam que a "guerra às drogas" pode estimular crimes contra a vida (Fajnzylber et al., 1998; Goncalves, 2019).

Os coeficientes reportados pela variável arma de fogo são positivos e significativos na maioria das especificações para o ICrimeSP - Vida. Assim, se a quantidade de apreensões sinaliza o estoque de armas nas mãos da população (Jorge, 2020), na média, quanto maior esse estoque, maiores os crimes contra a vida. Ou seja, quanto maior a presença de indivíduos potencialmente armados em dado município, maior a probabilidade de fatalidades e ferimentos de terceiros (criminosos, policiais ou civis). Isso porque é plausível esperar que as armas sejam mais difundidas entre criminosos do que entre pessoas que as utilizariam para autodefesa. A literatura que analisa as interfaces entre armas de fogo e crimes de homicídios é ampla e, no geral, também sinaliza uma relação positiva (Kleck e Patterson, 1993; Lott e Mustard, 1997; Hartung e Pessoa, 2010; Peres et al., 2012; Siegel et al., 2013; Marchezini e Kuwahara, 2018). Ressalva-se que também há evidências e justificativa - efeito dissuasão - para uma relação homicídios-armas negativa (Moody, 2010).

Destaca-se, ainda, que entre as variáveis de deterrence, ou seja, segurança pública, segurança privada e detenção, apenas a última reporta significância estatística e sinal negativo em grande parte das especificações. Tal evidência é coerente à fundamentação teórica, sugerindo que o aumento da produtividade policial - que, em última instância, afere as chances de o criminoso ser capturado - eleva o custo de oportunidade do crime e, por conseguinte, reduz a ocorrência de ações ilegais. Além disso, é um resultado consistente a outras evidências da literatura. Por exemplo, corrobora os indícios de Marchezini e Kuwahara (2018), no sentido de que a "eficiência policial" tem papel importante para a redução da criminalidade. Os resultados também sugerem que o impacto da detenção nos crimes contra o patrimônio é maior do que nos crimes 
contra vida - o que é sinalizado pelas diferenças das magnitudes dos coeficientes da variável detenção. Como os crimes contra a vida são mais atrelados a conflitos sociais, é razoável que o policiamento tenha maior poder dissuasivo sobre roubos e furtos.

Um problema intrínseco aos últimos resultados é que os impactos da detenção nos crimes, em especial os contra o patrimônio, podem ser inferiores aos seus potenciais. Por um lado, pode existir uma descrença das pessoas em relação à polícia. A título de ilustração, para o Paraná e o Rio Grande do Sul, Shikida (2020) entrevistou 302 presas e presos em decorrência de crimes contra o patrimônio (ou "crimes econômicos" ou "lucrativos"). Para 75\% dos entrevistados, o benefício econômico do crime era maior que o seu custo e para 18\% era igual, sendo o descrédito em relação à polícia um aspecto relevante. Por outro lado, a polícia pode realmente estar aquém de sua produtividade máxima.

\section{Considerações finais}

Este estudo investigou os efeitos do desenvolvimento econômico na criminalidade. Para isso, foram propostos e calculados dois índices de criminalidade para os municípios de São Paulo: o ICrime SP - Vida (crimes contra a vida) e o ICrimeSP - Patrimônio (crimes contra o patrimônio). Tais índices foram utilizados em análises descritivas para caracterizar a evolução recente da violência no estado (2007 a 2016). Além disso, em regressões em painel, foram analisadas as variáveis dependentes para investigar se os possíveis efeitos do desenvolvimento econômico na criminalidade são heterogêneos no tempo e em função dos tipos de crimes avaliados (contra a vida e contra o patrimônio), das dimensões do desenvolvimento e de regiões do estado (região metropolitana, litoral e interior). Como proxies para o desenvolvimento, foram utilizados os Índices FIRJAN de Desenvolvimento Municipal (IFDM) para duas dimensões: emprego-renda e educação. As regressões em painel foram realizadas com dados municipais de 2007 a 2016 e empregando um método de momentos generalizados (System-GMM).

Primeiramente, as análises descritivas apontaram que os índices de criminalidade apresentam expressivas disparidades entre os recortes geográficos considerados. Enquanto, na média, os crimes contra a vida reduziram em todo estado, com queda mais acentuada na RMSP, o mesmo não ocorreu nos crimes contra o patrimônio, que reportaram crescimento médio nos municípios dessa região. Já nas estimações econométricas, o primeiro destaque refere-se ao fato de os resultados terem sido robustos para inferir a existência de um efeito inercial na criminalidade, tanto contra a vida como contra o patrimônio. Ou seja, quanto maior a criminalidade em um ano, mais elevada ela tende a ser no próximo ano, o que caracteriza uma tendência de crescimento da criminalidade ao longo do tempo.

Quanto ao nível de desenvolvimento na dimensão emprego-renda, os resultados das regressões sinalizaram efeitos heterogêneos temporais (apenas em nível) e conforme o tipo do crime. Melhoras nessa dimensão foram associadas a reduções médias 
nos crimes contra a vida. Já nos crimes contra o patrimônio, os resultados foram robustos para não refutar a possibilidade de um efeito positivo do desenvolvimento do emprego-renda. Como discutido neste estudo, tal resultado é consistente a outras evidências da literatura e justificado pelo provável aumento do benefício líquido de roubos e furtos.

Para o desenvolvimento pela dimensão educação (IFDM Educação), os resultados sugeriram efeitos distintos aos obtidos no emprego-renda. Primeiramente, na média para todos os municípios, a dimensão educação foi associada a reduções nos crimes contra a vida e não foi observado efeito nos crimes contra o patrimônio - exceto na RMSP comparativamente ao interior. Assim, no caso dos crimes contra a vida, os resultados não refutaram a hipótese de que melhoras nos níveis educacionais aumentam o custo de oportunidade de práticas criminosas. Considerando o conjunto de resultados, é possível aprofundar a interpretação, sugerindo que o índice de desenvolvimento educacional capta, implicitamente, os efeitos da educação como uma trava moral aos crimes contra a vida; ou seja, um indutor de maiores noções de moralidade e civilidade e de custos psíquicos de desobedecer às leis.

Ressalta-se que, condicionais às covariadas, não há robustez nos resultados para uma atribuição ampla de efeitos heterogêneos espaciais ao desenvolvimento econômico nos dois tipos de crimes. Além disso, três resultados relativos aos regressores merecem destaque. O primeiro refere-se aos impactos positivos das ocorrências policiais de entorpecentes, principalmente motivadas pelo tráfico, na incidência de crimes contra o patrimônio e, no caso do tráfico, também nos crimes contra a vida. Por um lado, isso pode decorrer de externalidades dessa ação criminosa e de ela ser dominada, no estado de São Paulo, por grandes facções criminosas que se envolvem em outras práticas ilegais e em ações para acabar com a concorrência. Por outro lado, se o aumento das ocorrências de tráfico decorrer de ações de "guerra às drogas" da justiça e polícia, um efeito adverso seria o estímulo a crimes violentos.

O segundo resultado é o papel da produtividade policial na redução de crimes contra a vida e o patrimônio. Essa evidência é consistente com a literatura, sinalizando que o crescimento das chances de ser capturado, ao elevar o custo de oportunidade do crime, diminui a ocorrência de práticas ilegais. Ademais, os resultados apontaram que o impacto nos crimes contra o patrimônio é superior; ou seja, o policiamento tem maior poder dissuasivo nos roubos e furtos do que em homicídios. Ressalva-se que, se a produtividade policial não for a máxima ou se a população estiver descrente em relação à polícia - aspectos que podem ser investigados para o estado de São Paulo em trabalhos futuros -, os efeitos supracitados seriam ainda maiores. O terceiro resultado é o efeito positivo das armas de fogo sobre os crimes contra a vida, o que pode estar relacionado a diversos fatores, como a maior proporção de armas nas mãos de criminosos e as maiores chances de confrontos com arma resultarem em mortes.

Portanto, o presente estudo encontrou efeitos heterogêneos do desenvolvimento econômico na incidência de crimes. Assim, sinaliza uma complexa cadeia causal e 
reforça a dificuldade em levantar os condicionantes econômicos, sociais e de políticas públicas de segurança, comuns a todos os crimes e para diferentes especificidades locacionais, que subsidiem o estabelecimento de ações genéricas de prevenção e combate ao crime. Tal dificuldade reflete-se na complexidade da realização de avaliações empíricas que consigam lidar com todas as fontes de potenciais vieses, principalmente decorrentes de problemas de endogeneidade. Este estudo adotou algumas estratégias empíricas para tentar lidar com o problema, resultando em evidências adicionais para o debate e, ao mesmo tempo, consistentes com outras existentes, o que sinaliza certo sucesso das estratégias empíricas adotadas. Mesmo assim, fica como sugestão a trabalhos futuros avaliações com os mesmos objetivos norteadores, mas com a implementação de outras estratégias de identificação para garantir ainda mais evidências ao debate.

\section{Referências}

Araujo Jr, A. F. e Fajnzylber, P. (2000). Crime e economia: um estudo das microrregiões mineiras. Revista Econômica do Nordeste, 31(1):630-643.

Arellano, M. e Bond, S. (1991). Some tests of specification for panel data: Monte carlo evidence and an application to employment equations. The Review of Economic Studies, 58(2):34-65.

Arellano, M. e Bover, O. (1995). Another look at the instrumental variable estimation of error-components models. Journal of Econometrics, 68(1):29-51.

Baltagi, B. (2001). Econometric Analysis of Panel Data.

Barros, L. C. e Gomes, F. A. R. (2008). Desigualdade e desenvolvimento: a hipótese de Kuznets é válida para os municípios. Análise Econômica, 26(50):1-28.

Barros, P. H. B., Baggio, I. S., Stege, A. L., e Hilgemberg, C. M. A. T. (2019). Economic development and crime in brazil: a multivariate and spatial analysis. Revista Brasileira de Estudos Regionais e Urbanos, 13(1):1-22.

Becker, G. S. (1968). Crime and punishment: An economic approach. Journal of Political Economy, 76(2):169-217.

Becker, K. L. e Kassouf, A. L. (2017). Uma análise do efeito dos gastos públicos em educação sobre a criminalidade no brasil. Economia e Sociedade, 26(59):215-242.

Blundell, R. e Bond, S. (1998). Initial conditions and moment restrictions in dynamic panel data models. Journal of Econometrics, 87(1):115-143.

Brasil (1940). Lei no 2.848. Código Penal. Brasília, DF, 7 de dezembro.

Brasil (1984). Lei $n^{\circ}$ 7.209. Altera dispositivos do Decreto-Lei $\mathrm{n}^{0} \mathbf{2 . 8 4 8}$. Brasília, DF, 11 de julho. 
Brasil (2018). Lei no 13.654. Altera o Decreto-Lei no 2.848.. Brasília, DF, 23 de abril.

Brasil (2019). Lei no 13.964. Aperfeiçoa a legislação penal e processual penal. Brasília, DF, 24 de dezembro.

Britto, C. Q. (2017). Violência e homicídios relacionados ao tráfico de drogas, em Uberlândia-MG. Tese (Doutorado em Geografia) - Instituto de Geografia, Universidade Federal de Uberlândia. Uberlândia.

Cerqueira, D., Lima, R. S., Neme, C., Ferreira, H., Pinheiro, M., e Marques, D. (2018). Atlas da violência. Instituto de Pesquisa Econômica Aplicada, Brasília, Distrito Federal.

Cerqueira, D., Lima, R. S., Neme, C., Ferreira, H., Pinheiro, M., e Marques, D. (2019). Atlas da violência. Instituto de Pesquisa Econômica Aplicada, Brasília, Distrito Federal.

Cerqueira, D. e Lobao, W. (2003). Determinantes da criminalidade: uma resenha dos modelos teóricos e resultados empíricos. Textos para Discussão do IPEA, n. 956.

Cerqueira, D. R. (2010). Causas e consequências do crime no Brasil. Página Tese de Doutorado em Economia, PUC, Rio de Janeiro.

Cerqueira, D. R. C. e Coelho, D. S. C. (2015). Redução da idade de imputabilidade penal, educação e criminalidade. Nota Técnica, n. 15, DIEST, IPEA.

CNI (2018). Propostas da indústria para as eleições - segurança pública: a importância da governança. Confederação Nacional da Indústria, cadernos n. 03, Brasília.

Cortes, R. X., Fochezatto, A., e Jacinto, P. A. (2018). Crimes nos municípios do Rio Grande do Sul: análise a partir de um índice geral de criminalidade. Estudos Econômicos, 48(3):451-487.

Dirk, R. e Moura, L. (2017). As motivações nos casos de letalidade violenta da Região Metropolitana do Rio de Janeiro. Cadernos de Segurança Pública, ano 9.

Duenhas, R. A., Goncalves, F. O., e Gelinski Junior, E. (2014). Educação, Segurança Pública e Violência nos Municípios brasileiros: uma análise de painel de dados dinâmico. Publicatio UEPG Ciências Sociais, 22(2):119-128.

Durlauf, S. N. e Nagin, D. S. (2011). Imprisonment and crime: can both be reduced? Criminology \& Public Policy, 10(1):13-54.

Espinheira, G. (2006). Os tempos e os espaços do crime. Disciplina Espaço Público e Cidadania, II Curso de Especialização em Políticas e Gestão em Segurança Pública, CEGESP/RENAESP.

Fajnzylber, P., Lederman, D., e Loayza, N. (1998). Determinants of crime rates in Latin America and the world: an empirical assessment. World Bank Latin American and Caribbean Studies. World Bank, Washington, D.C. 
Fernandes, N. e Fernandes, V. (2002). Criminologia integrada. $2^{\mathrm{a}}$ ed. São Paulo: Revista dos Tribunais.

Ferreira, S. P., Lima, R. S., e Bessa, V. (2009). Criminalidade violenta e homicídios em São Paulo: fatores explicativos e movimentos recentes. In: MINISTÉRIO DA JUSTIÇA. Homicídios: políticas de prevenção e controle. Coleção Segurança com Cidadania, v. III, Ministério da Justiça, Brasília.

FIRJAN (2018). Metodologia: Índice FIRJAN de Desenvolvimento Municipal (IFDM). Federação da Indústrias do Estado do Rio de Janeiro, Rio de Janeiro.

Freitas, T. A., Cadaval, A. F., e Goncalves, G. A. (2017). A estimação de um índice geral de criminalidade para os municípios do Rio Grande do Sul - IGcrime RS. Ensaios FEE, 38(3):499-520.

Galiani, S., Gertler, P., e Schargrodsky, E. (2005). Water for life: the impact of the privatization of water services on child mortality. Journal of Political Economy, 113(1):34-53.

Glaeser, E. L., Kallal, H. D., Scheinkman, J. A., e Shleifer, A. (1992). Growth in cities. Journal of Political Economy, 100(6):1126-1152.

Goldstein, P. J. (1985). The Drugs/Violence Nexus: A Tripartite Conceptual Framework. Journal of Drug Issues, 39(1):143-174.

Gomes, C. E., Evangelista, T. F., Lima, R. L., e Parre, J. L. (2014). Determinantes do crime nos municípios de Minas Gerais e seus possiveis spillovers espaciais. Revista Economia Ensaios, 31(2):67-91.

Goncalves, R. S. (2019). O efeito contrário da guerra às drogas: aumento da violência e propagação do preconceito. Disponivel em: https://jus.com.br/. Acesso em: 16 de jul. 2020.

Greene, W. H. (1997). University of Michigan, Econometric Analysis. 3ª ed. Michigan.

Guimaraes, J. L. C. (2014). Motivações do crime segundo o criminoso: condições econômicas, interação social e herança familiar. Revista Brasileira de Segurança Pública, 8(1):34-67.

Hartung, G. e Pessoa, S. (2010). O papel das armas de fogo na queda dos homicídios em São Paulo. Disponível em: http://www.anpec.org.br/encontro2010/inscricao/ arquivos/000-7d866aaee3788286bc1b1c7465d22305 pdf. Acesso em: 1 de jul. 2020.

Jorge, M. A. (2020). Uma análise da mensuração da disponibilidade de armas de fogo no Brasil. Economic Analysis of Law Review, 11(2):97-125.

Justus, M., Cerqueira, D. R. C., Kahn, T., e Moreira, G. C. (2018). The "São Paulo Mystery": The role of the criminal organization PCC in reducing the homicide in 2000s. EconomiA, 19(2):201-218. 
Kahn, T. (2005). Secretaria de Segurança Pública de São Paulo, Estatística de criminalidade: manual de interpretação. $1^{\underline{a}}$ ed. São Paulo.

Kahn, T. (2013). Crescimento econômico e criminalidade: uma interpretação da queda dos crimes no Sudeste e aumento no Norte/Nordeste. Revista Brasileira de Segurança Pública, 7(1):152-164.

Kleck, G. e Patterson, E. B. (1993). The impact of gun control and gun ownership levels on violence rates. Journal of Quantitative Criminology, 9(3):249-287.

Kume, L. (2004). Uma estimativa dos determinantes da taxa de criminalidade brasileira: uma aplicação em painel dinâmico. Disponível em: https://econpapers . repec.org/paper/anpen2004/148.htm. Acesso em: 1 de jul. 2020.

Lima, M. L. C., Ximenes, R. A. A., Souza, E. R., Luna, C. F., e Albuquerque, M. F. P. M. (2005). Spatial analysis of socioeconomic determinants of homicide in Brazil. Revista de Saúde Pública, 39(2):176-182.

Lochner, L. (2011). Education policy and crime. University of Chicago Press. Cook, P.; Ludwig, J.; McCrary, J. (Eds.). Controlling crime: strategies and tradeoffs. Chicago.

Lott, J. R. e Mustard, D. B. (1997). Crime, deterrence and right-to-carry concealed handguns. Journal of Legal Studies, 26(2):1-68.

Marchezini, B. R. e Kuwahara, M. Y. (2018). O papel das armas nos homicídios na Região Metropolitana de São Paulo. Revista Economia Mackenzie, 15(2):43-56.

Mariano, R. S. (2010). Fatores socioeconômicos da criminalidade no Estado de São Paulo: um enfoque da economia do crime. Dissertação (Mestrado em Economia Política) - Programa de Pós-Graduação em Economia Política. Pontifícia Universidade Católica de São Paulo, São Paulo.

Marques Jr, K. (2014). Renda, desigualdade e criminalidade no Brasil: uma análise empírica. Revista Econômica do Nordeste, 45(3):34-46.

Merton, R. K. (1938). Social structure and anomie. American Sociological Review, 3(5):672-682.

Monteiro, J. B. (2009). Indicador de criminalidade geral baseado em métodos multivariados e estatística espacial para controle na segurança pública. Trabalho de Conclusão de Curso (Graduação em Estatística) - Instituto de Matemática, Universidade Federal do Rio Grande do Sul. Porto Alegre. Página 85.

Moody, C. (2010). Edward Elgar, Firearms and Homicide. In: BENSON, B.; ZIMMERMAN, P. (eds.). Handbook on the Economics of Crime. Cheltenham.

Mustard, D. B. (2003). Reexamining criminal behavior: the importance of omitted variable bias. Review of Economics and Statistics, 85(1):205-211. 
Oliveira, C. A. e Johnston, F. L. (2017). Efeitos Dissuasórios de Ações Policiais sobre Roubos na Região Metropolitana de Porto Alegre. Revista da AMDE-ANO, 17(2):146180.

Oliveira, J. (2016). Avaliação dos resultados do pacto pela vida e a dinâmica dos homicídios nos municípios de Pernambuco. Dissertação (Mestrado em Ciência Política) - Centro de Filosofia e Ciências Humanas, Universidade Federal de Pernambuco. Recife.

Peres, M. F. T., Almeida, J. F., Vicentin, D., Cerda, M., Cardia, N., e Adorno, S. (2011). Queda dos homicídios no Município de São Paulo: uma análise exploratória de possiveis condicionantes. Revista Brasileira Epidemiologia, 14(4):709-721.

Peres, M. F. T., Almeida, J. F., Vicentin, D., Ruotti, C., Nery, M. B., Cerda, M., Cardia, N., e Adorno, S. (2012). Evolução dos homicídios e indicadores de segurança pública no Município de São Paulo entre 1996 e 2008: um estudo ecológico de séries temporais. Ciência \& Saúde Coletiva, 17(1):237-254.

Pinto, A. M., Farias, J. J., Costa, R. F., e Lima, F. S. (2018). Uma análise dos determinantes da taxa de crimes de homicídios nos estados do Brasil: uma aplicação em painel dinâmico. Revista de Economia Regional, Urbana e do Trabalho, 7(2):35-52.

Plassa, W., Paschoalino, P. A. T., e Santos, M. P. (2019). Determinantes socioeconômicos das taxas de homicídios no nordeste brasileiro: uma análise espacial. Planejamento e Políticas Públicas, 53(1):459-476.

Santos, F. F. S. (2008). Um partido, três agendas? Política de Segurança Pública no estado de São Paulo (1995-2006). Tese (Doutorado em Administração) - Escola de Administração de Empresas de São Paulo, Fundação Getúlio Vargas. São Paulo.

Santos, M. J. (2009). Dinâmica temporal da criminalidade: mais evidências sobre o "efeito inércia" nas taxas de crimes letais nos Estados brasileiros. Revista Economia, 10(1):169-194.

Santos, M. J. e Kassouf, A. L. (2007). Uma investigação econômica da influência do mercado de drogas ilícitas sobre a criminalidade brasileira. Revista Economia, 8(2):187-210.

Santos, M. J. e Kassouf, A. L. (2008). Estudos econômicos das causas da criminalidade no Brasil: evidências e controvérsias. Revista Economia, 9(2):343-372.

Sen, A. (2000). Companhia das Letras, Desenvolvimento como Liberdade. $1^{\mathfrak{a}}$ ed. São Paulo.

Shaw, C. R. e Mckay, H. D. (1942). University of Chicago Press, Juvenile deliquency and urban areas. Chicago.

Shikida, P. F. A. (2008). Crimes violentos e desenvolvimento socioeconômico: um estudo para o estado do Paraná. Direitos Fundamentais \& Justiça(5):127-132. 
Shikida, P. F. A. (2020). Uma análise da Economia do Crime em estabelecimentos penais paranaenses e gaúchos: o crime compensa? Revista Brasileira de Execução Penal, 1(1):45-53.

Siegel, M., Ross, C. S., e King, C. (2013). The relationship between gun ownership and firearm homicide rates in the United States, 1981-2010. American Journal of Public Health, 103(11):2098-2105.

Silva, F. O. (2013). Banco de dados aplicado na análise da criminalidade e índices de desenvolvimento do Brasil. Trabalho de Conclusão de Curso (Tecnólogo em Análise e Desenvolvimento de Sistemas) - Curso de Tecnologia em Análise e Desenvolvimento de Sistemas, Universidade Tecnológica Federal do Paraná. Medianeira. Página 158.

Silva, V. A., Moura, F. R., Esperidião, F., e Baptista, C. H. M. S. (2019). Desigualdades socioeconômicas: uma análise sobre os determinantes da taxa de mortalidade infantil nos municípios brasileiros. Revista Brasileira de Estudos Regionais e Urbanos, 13(1):541-568.

Silva, V. A., Moura, F. R., Esperidião, F., Baptsilveira, D., e Alvarenga, Dista, C. H. M. S. (2020). Renda domiciliar per capita foi de $R \$ 1.439$ em 2019, diz IBGE.

Soares, T. C., Zabot, U. C., e Ribeiro, G. M. (2012). Índice geral de criminalidade: uma abordagem a partir da análise envoltória de dados para os municípios catarinenses. Leituras de Economia Política(19):12-31.

Souza, A. R. (2019). A criminalidade no estado de Pernambuco: uma análise espacial dos determinantes das ocorrências de homicídios e roubos. Revista de Estudos Sociais, 21(43):4-27.

Souza, L. A. F. (2003). Crimes violentos: desafios para uma política de segurança pública. Jornal de Psicologia-PSI(135):178-201.

Teixeira, E. C. (2011). Dois ensaios acerca da relação entre criminalidade e educação. Tese (Doutorado em Economia) - Escola Superior de Agriculta "Luiz de Queiroz", Universidade de São Paulo. Piracicaba.

Theodoro, M. I. A. (2011). Um estudo da relação entre polarização de renda e criminalidade para o Brasil. Dissertação (Mestrado em Economia) - Faculdade de Economia, Administração e Contabilidade de Ribeirão Preto, Universidade de São Paulo. Ribeirão Preto.

UNODC (2019). United Nations Office on Drugs and Crime, Global Study on Homicide 2019. Vienna.

Waiselfisz, J. J. (2016). Faculdade Latino-Americana de Ciências Sociais (Flacso), Mapa da violência 2016: homicídios por armas de fogo. Brasília.

(๔) Este artigo está licenciado com uma CC BY 4.0 license. 